\title{
Tool use and language share syntactic processes and neural patterns in the ba- sal ganglia
}

Simon Thibault ${ }^{1,2^{*}}$, Raphaël Py ${ }^{1,2}$, Angelo Mattia Gervasi ${ }^{1}$, Romeo Salemme ${ }^{1}$, Eric Koun ${ }^{1}$, Martin Lövden $^{3,4}$, Véronique Boulenger ${ }^{2,5 \dagger}$, Alice C. Roy ${ }^{2,5 \dagger}$, Claudio Brozzoli1 ${ }^{1,2,3 \dagger^{*}}$

${ }^{1}$ Integrative Multisensory Perception Action \& Cognition Team (ImpAct), Centre de Recherche en Neurosciences de Lyon, INSERM U1028, CNRS UMR5292, Lyon, 69000, France.

${ }^{2}$ University of Lyon, Lyon, 69000, France.

${ }^{3}$ Aging Research Center (ARC), Department of Neurobiology, Care Sciences and Society, Karolinska Institutet, Stockholm, Sweden.

${ }^{4}$ Department of Psychology, University Gothenburg, Gothenburg, Sweden

${ }^{5}$ Dynamics of Language, CNRS UMR5596, Lyon, France.

*Corresponding authors E-mail: simon.thibault@ inserm.fr, claudio.brozzoli@ inserm.fr

$\dagger$ Equal contributions. 
Does tool use share syntactic processes with language? Acting with a tool is thought to add a hierarchical level into the motor plan. In the linguistic domain, syntax is the cognitive function handling interdependent elements. Using fMRI, we detected common neurofunctional substrates in the basal ganglia subserving both tool use and syntax in language. The two abilities elicited similar patterns of neural activity, indicating the existence of shared functional resources. Manual actions and verbal working memory did not contribute to this common network. In line with the existence of shared neural resources, we observed bidirectional behavioral enhancement of tool use and syntactic skills in language so that training one function improves performance in the other. This reveals supramodal syntactic processes for tool use and language.

One Sentence Summary: Syntactic processes in the basal ganglia subserve both tool use and language such that training one ability boosts the other. 
Tool use is a highly sophisticated skill whose sensory (1) and motor components (2) have been extensively studied across disciplines. Tool use has been suggested to add a further hierarchical level to the motor plan (3-5). Interdependent elements and hierarchies are common in language, and decades of research have pointed to syntax as the cognitive function handling complex linguistic structures (6). Does tool use share syntactic processes with language? A wide range of cognitive processes exploit activity in sensorimotor regions (7 - 13). We posit that syntactic processes are also grounded in sensorimotor structures.

Center-embedded object relative sentences (14-16) provide a paradigmatic example of complex linguistic structures (Table 1A). Embedded clauses split interdependent elements and add further dependencies in the sentence. However, by handling hierarchical sequential elements, syntactic processes allow us to understand such complex structures. Studies suggest that action and language share syntactic processes (17-21). Actions involve hierarchies of interdependent subcomponents within an entire motor sequence (22-25). Dexterous tool use, in particular, implies incorporating an external object (1). The functional combination of the body and the external object to perform an action (3) embeds a further level into the manual motor program (26). Goal-directed movements feature several subcomponents integrated in the action sequence (27), such as reaching, grasping, lifting, rotating and placing an object. This sequence provides an example of complex motor structures with several elements whose relationship needs to be subtly rearranged when the tool is embedded in the motor program $(28,29)$. An individual's tool-use dexterity in such a motor task predicts linguistic production skills in a syntactically constrained task (30). Neuroimaging supports the behavioral link between tool use and language. Syntactic processing managing linguistic hierarchical structures indeed relies on activity within the left inferior frontal gyrus [1IFG; $(6,14-16)]$ and basal ganglia [BG; $(21,31,32)]$, in particular, within the striatum $(33,34)$. Similarly, activity in a parieto-frontal network as well as in the BG supports skillful tool use (35-37). Brain imaging 
studies have therefore described partially overlapping neural networks for syntax $(15,21,33)$ and tool use (35-38). These lines of research have however so far diverged, and the anatomo-functional overlap between tool use and syntax remains anecdotal. Here we tested the hypothesis that tool use and syntax share neural resources and, as a consequence, that the two abilities impact one another at the behavioral level.

\section{Anatomical overlap of tool use and syntactic activity in the basal ganglia}

We first mapped the brain regions where tool use and syntactic processes overlap with fMRI. To isolate the syntactic network, 20 participants solved a task requiring to process center-embedded relative clauses $(14,15)$ (Experiment 1, Fig. 1A). The protocol consisted of the presentation of sentences relying on the same content words but featuring three different syntactic structures: either a coordinated (e.g., "The writer admires the poet and reads the paper"), subject relative (e.g., "The writer that admires the poet reads the paper") or object relative clause (e.g., "The writer that the poet admires reads the paper"; Table 1A). Each sentence was followed by a test affirmation (e.g., "The poet admires the writer"; Table 1B), which the participants had to judge as true or false with respect to the immediately preceding sentence. The participants succeeded in this task (Fig. 1B) revealing, as expected, the worst sensitivity $\left(d^{\prime}\right)$ scores and the longest reaction times (RTs) for the object relatives (mean \pm SEM: $d^{\prime}=1.25 \pm 0.12$; RTs $=1769 \pm 97 \mathrm{~ms}$ ) compared to both subject relatives $\left(d^{\prime}=1.98 \pm 0.06 ;\right.$ RTs $=1519 \pm 76 \mathrm{~ms} ; p_{s}<0.001$, Tukey post hoc $)$ and coordinated clauses $\left(d^{\prime}=2.01 \pm 0.06 ; \mathrm{RTs}=1487 \pm 87 \mathrm{~ms} ; p_{s}<0.001\right)$. No difference was found between coordinated and subject relative clauses $\left(p_{s}>0.74\right)$. This pattern reflects the increased syntactic complexity of the object relatives with respect to the two other conditions (14). We assessed the functional syntactic network by contrasting brain activity elicited during the presentation of the object relatives with that elicited during the presentation of the two other sentence types. This 
window of interest targeted the processes underlying syntactic encoding of the sentence material rather than processes engaged in sentence reorganization to answer the affirmation test (15). The syntactic network consisted of activity in a parieto-frontal ensemble of cortical areas (Table S1A) as well as subcortically within the $\mathrm{BG}\left(p_{s}-f w e<0.05\right.$ at the cluster level), encompassing the bilateral caudate nuclei, internal globus pallidus (GPi) and putamen. Frontal activity was observed within the IIFG $(p<0.001$ unc.) in a cluster localized in Broca's area (Fig. 1C). 


\section{(A) Sentence Encoding}

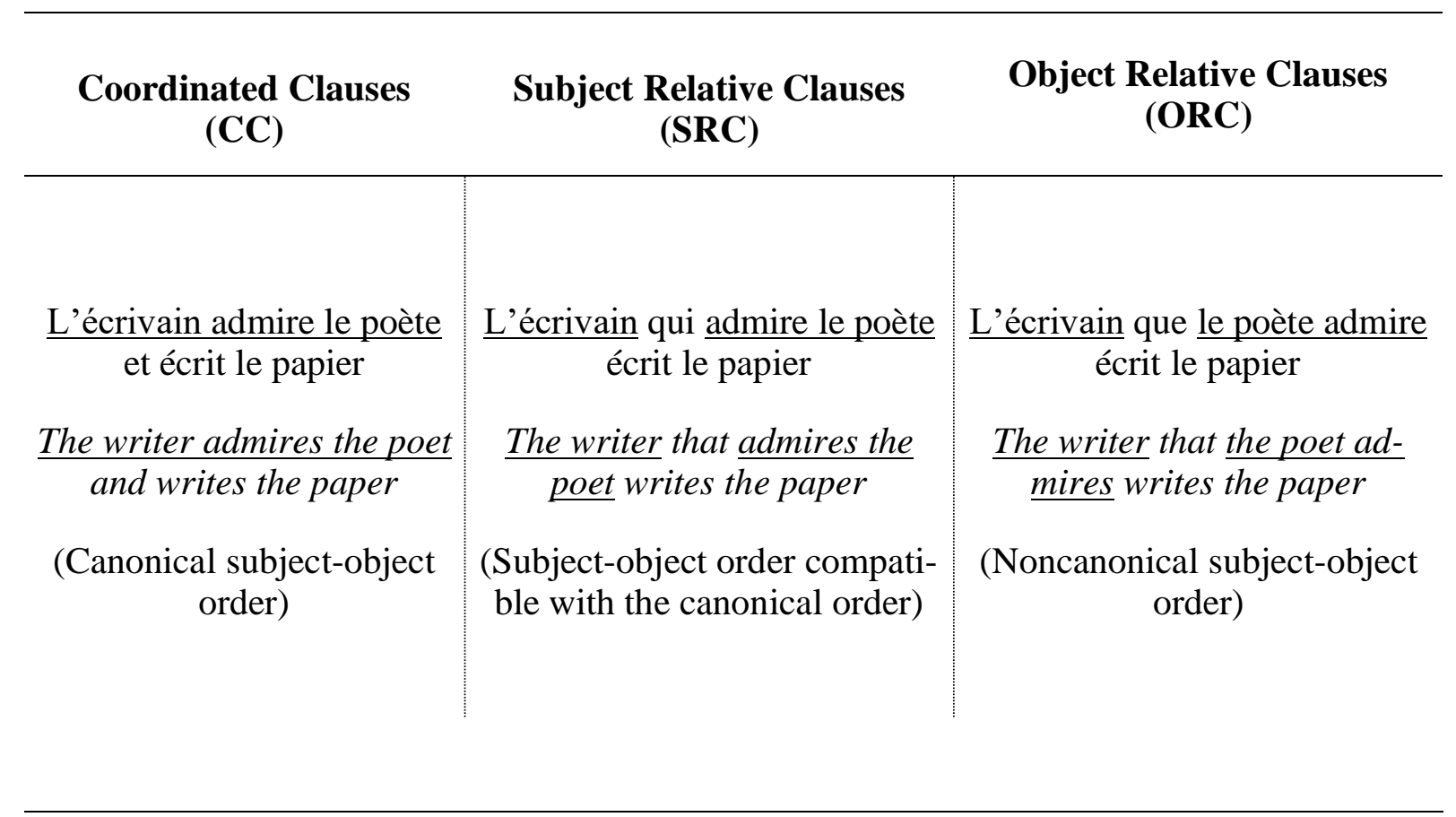

(B) Test Affirmation (one selected among the four)

\begin{tabular}{|c|c|}
\hline L'écrivain admire le poète & Le poète admire l'écrivain \\
\hline The writer admires the poet & The poet admires the writer \\
\hline$(C C=$ True $-S R C=$ True - ORC $=$ False $)$ & $(\mathrm{CC}=$ False $-\mathrm{SRC}=$ False $-\mathrm{ORC}=$ True $)$ \\
\hline Le poète écrit le papier & L'écrivain écrit le papier \\
\hline The poet writes the paper & The writer writes the paper \\
\hline$(\mathrm{CC}=$ False $-\mathrm{SRC}=$ False $-\mathrm{ORC}=$ False $)$ & $(C C=$ True $-\mathrm{SRC}=$ True $-\mathrm{ORC}=$ True $)$ \\
\hline
\end{tabular}

Table. 1. Syntactic task: comprehension of sentences in a 2-alternative forced choice (2-AFC) task. (A) Syntactic structures presented during the sentence-encoding phase. (B) Test affirmation for the 2-AFC task (2 true and 2 false possible probes for each encoded sentence). 
To identify the overlap between the syntactic and tool-use networks, we required the same participants to use a pair of $30 \mathrm{~cm}$-long pliers, or their free right hand in different trials, to move a peg from one side of a board to the other (Fig. 1D and Movies S1 and S2). We recorded their brain activity while they prepared and executed the movement with the tool or their free hand. The planning phase engages processes necessary to the organization of the components of the subsequent action (24), and is not influenced by the visual differences present during overt movement execution. We therefore isolated the activity specifically related to the preparation of movements with the tool and subtracted the activity related to preparation of manual movements and to movement execution with the tool and the hand (see Supplementary Text for contrasts defined to investigate planning and execution of free-hand actions and tool-use execution). Tool-use planning involved a network encompassing parietal and prefrontal areas (Table S1B) as well as the BG $\left(p_{s}-f w e<0.05\right.$ at the cluster level), including the bilateral caudate nuclei, putamen and GPi (Fig. 1E). A frontal region within the IIFG ( $p<0.001$ unc.) was also activated, which was located in the ventral premotor cortex (PMv), an area more posterior than the area identified in the syntactic task. The syntactic and tool-use planning networks thus anatomically overlapped within the BG, sharing significant activations of the left caudate nucleus (1Cau) and bilateral GPi (Fig. 1F and Table S1C). Even though syntax and tool-use planning both relied on the IIFG, the respective clusters of activation did not overlap (even at a lenient threshold $p<0.005$ unc.). We employed a stringent contrast for tool-use planning (Fig. 1G-I), nonetheless we sought potential overlap between free-hand planning and syntax at the whole brain level but did not find any significant cluster of shared activation (Supplementary Text for the free-hand planning neural activity). Although syntax has been disentangled from working memory resources (15), the latter might still support the processing of complex syntactic structures. To rule out such contribution of working memory to the overlap between tool-use planning and syntactic networks, we measured brain activity in the same participants 
while they performed two verbal $n$-back tasks with two levels of difficulty (Fig. S1, Supplementary Text for behavioral results). Working memory mainly recruited a network involving the bilateral inferior parietal lobes (angular gyri), the left middle frontal gyrus and the left caudate (Fig. S2 and Table S2). The working memory brain map did not significantly overlap with the tool-use planning network. 
A

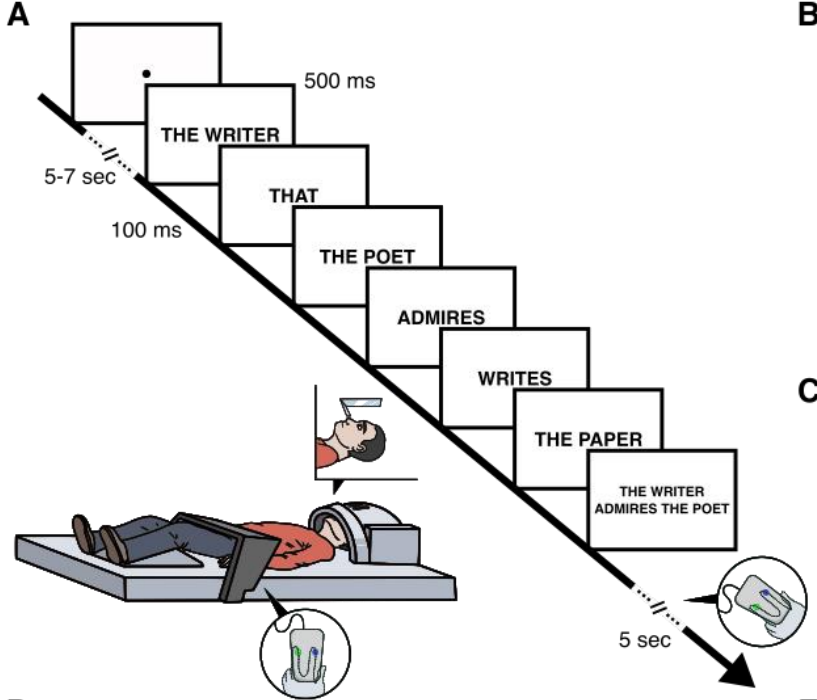

D

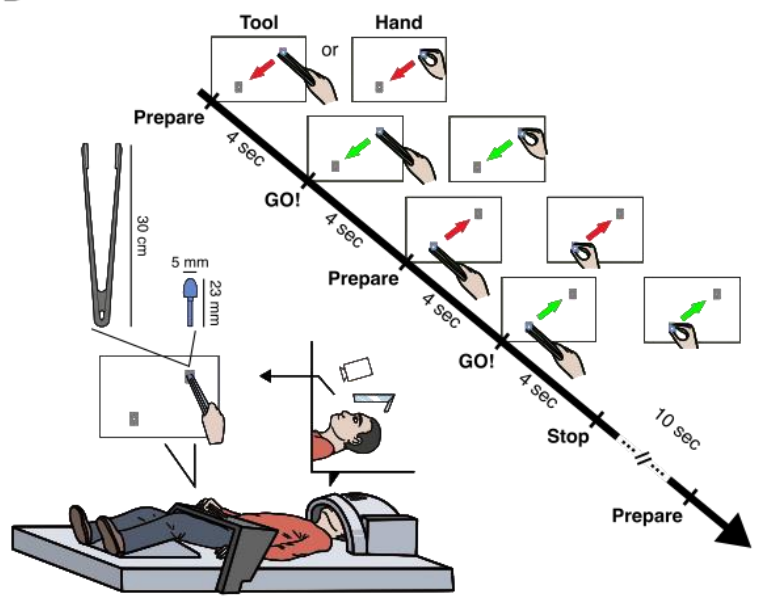

F
B
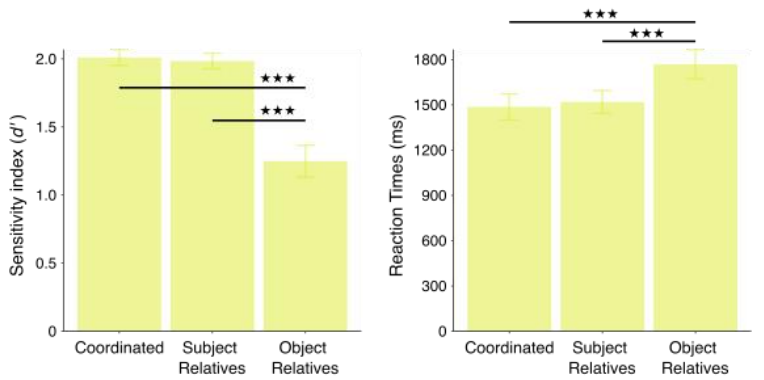

C

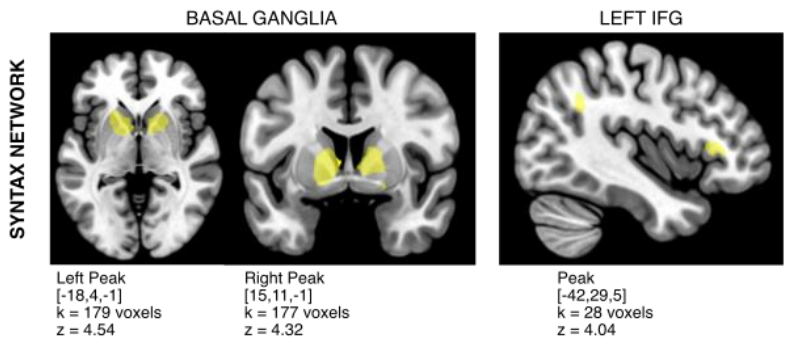

E
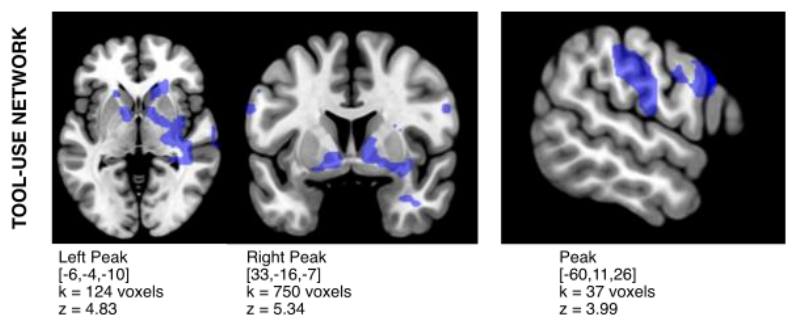

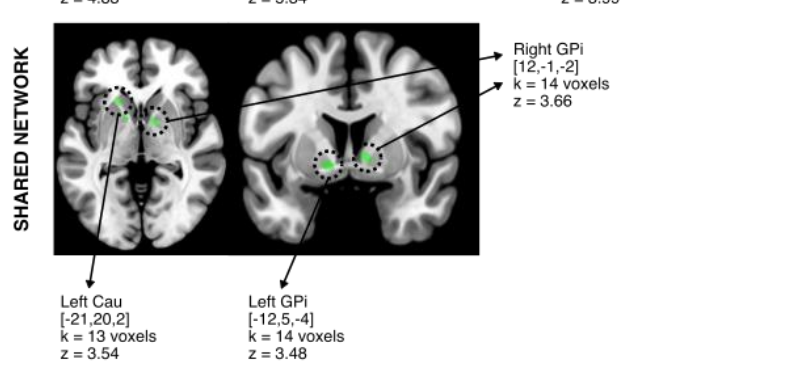

G

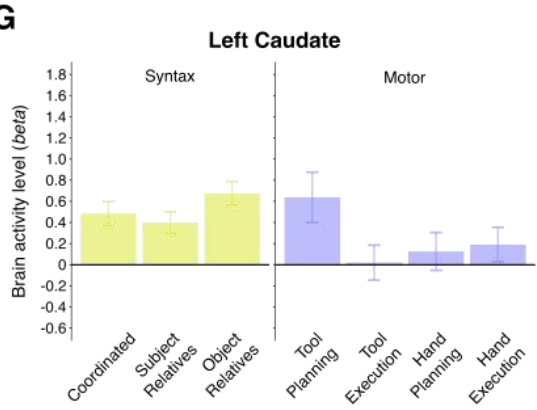

H
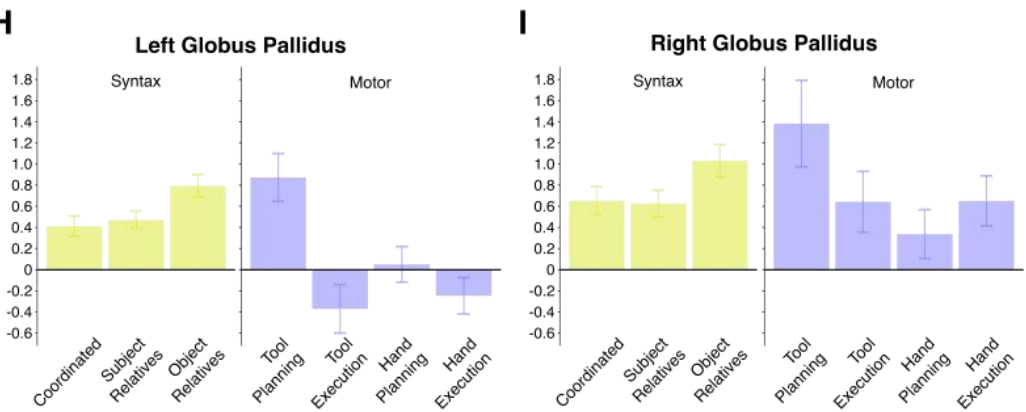

Fig. 1. Experiment 1: Overlap of syntax and tool-use planning activity. (A) Set-up and experimental design of the syntactic task. (B) Sensitivity index ( $d^{\prime}$, left graph) and Reaction Times (RTs; right graph) for the syntactic comprehension of the three sentence structures: both the one-way repeated measures ANOVA on the sensitivity $\left(d^{\prime}\right)$ and the linear mixed model on RTs showed a significant main effect of Sentence $\left(d^{\prime}: F_{(1.6,30.6)}=40.04 ; p<0.001 ; \eta_{G}^{2}=0.49\right.$; RTs: $\left.\chi^{2}(2)=25.21, p<0.001\right)$. Error bars show standard errors. ${ }^{* * *} p<0.001$, Tukey post hoc. (C) Statistical maps 
thresholded at $p<0.001$, unc., for syntax (object relatives compared to the two other sentence types). (D) Set-up and experimental design of tool-use and free-hand motor tasks. (E) Statistical maps thresholded at $p<0.001$, unc., for tool-use planning. (F) Joint neuronal activity for syntax and tool-use planning in the basal ganglia, thresholded at $p<$ 0.001, unc. (G-I) Average brain activity level in each cluster significantly activated by both tasks. The highest activations were found for tool-use planning (blue) and object relative clauses (yellow) in the motor and syntactic tasks, respectively. 


\section{Common neurocognitive resources for tool-use planning and syntax in the basal ganglia}

Does the neural overlap of activity subserving tool-use planning and syntax within the BG reflect common cognitive processes? In this case the same neural resources should be recruited across conditions. Accordingly, brain activities underlying tool-use planning and syntactic encoding during object relative sentences may show representational similarity in their respective spatial distribution within the overlapping clusters.

We therefore studied the representational similarity of brain activity patterns (41) across the two motor (tool-use and free-hand planning) and the two most complex linguistic conditions (object and subject relatives). Considering the overlapping voxels revealed by the conjunction analysis $(n=41)$, we tested two models, including the similarity expected between conditions of the same domain (tool use and free hand for the motor domain and object and subject relatives for the linguistic domain). The first model tested the hypothesis of cross-domain similarity between activity patterns for tool-use planning and object relatives. The second control model instead tested for cross-domain similarity between free-hand planning and object relatives. The model assessing the representational similarity between tool-use planning and object relatives was significant (Pearson's $r$ mean $=0.25 \pm 0.08 ;$ Fisher's $z$ mean $=0.29 \pm 0.10 ; \mathrm{t}_{(19)}=3.00 ; p=0.007$ Bonferronicorrected, Cohen's $d=0.66)$. In contrast, the second model testing for a similarity between freehand planning and object relatives did not yield a good fit for the data (Pearson's $r$ mean $=0.14 \pm$ $0.09 ;$ Fisher's $z$ mean $=0.19 \pm 0.11 ; \mathrm{t}_{(19)}=1.63 ; p=0.12$ Bonferroni-corrected). To test for the specificity of the similarity between tool-use and object relative patterns, we extracted the patterns elicited by the verbal working memory tasks (3-back and 1-back) on the same voxels and entered them in our models instead of the syntactic patterns. This did not reveal any significant similarity neither with tool-use nor with free-hand planning $\left(\mathrm{t}_{\mathrm{s}}<1.36 ; p_{\mathrm{s}}>0.18\right.$, Bonferroni-corrected; Supplementary Text). 
We further examined whether the reported significant similarity allows a classifier trained on the motor patterns (tool use and free hand) to coherently predict those elicited by object relatives. A successful cross-domain classification would corroborate the evidence for common neural resources shared by the two abilities. We applied a classification based MultiVoxels Patterns Analysis (MVPA) on the patterns of activity extracted from the overlapping voxels identified with the conjunction analysis $(\mathrm{N}=41)$. A Support Vector Machine (SVM) classifier was trained on the motor data (tool-use planning vs. free-hand planning) and tested cross-domain on the object relative data, with a leave-one-subject-out procedure. We assessed the accuracy of the classifier as the proportion of object relative neural patterns classified as tool-use patterns. An accuracy of 0.5 indicates that the classifier performed at chance. An accuracy significantly above chance level means that object relative patterns were classified more as tool-use than as free-hand patterns, whereas accuracy values significantly below 0.5 indicate the opposite. Object relative patterns were significantly classified as tool-use rather than free-hand planning patterns (accuracy $=0.87$, $p=0.003)$. When tested cross-domain on the working memory neural patterns (3-back) within the same voxels, the accuracy of the same classifier was not significantly different from chance level (accuracy $=0.64, p=0.15$, Supplementary Text).

As a further step, we computed voxelwise Pearson's correlation scores between activity levels supporting tool-use planning and successful comprehension of object relatives (42). These correlation scores were compared to correlation scores found between free-hand planning and object relative processing. We compared the difference between the two observed Pearson's $r$ values to an empirical null distribution of differences obtained after 10,000 permutations. The observed correlation between patterns for tool-use planning and object relative comprehension was significantly larger than that between free-hand planning and object relatives, both for the 1GPi and rGPi (1GPi: Pearson's $r$ difference $=0.61 ; p=0.03$ and $\mathrm{rGPi}$ : Pearson's $r$ difference $=0.79 ; p=0.007$; 
Fig.2A-F and Supplementary Text). The difference was not significant for the 1Cau (Pearson's $r$ difference $=-0.08 ; p=0.64)$.

Overall, these findings establish that tool use and syntax rely on neural activity within common anatomical territories in the BG. The activity independently elicited by the two tasks displays similar spatial distribution, which is consistent with common neural resources for the two tasks. It has been documented that when two functions share neural resources and cognitive processes, learning transfer occurs (39): training a specific ability can therefore benefit an untrained one $(39,40)$. Consequently, we predicted cross-domain learning transfer between tool use and syntactic skills in language. 
A

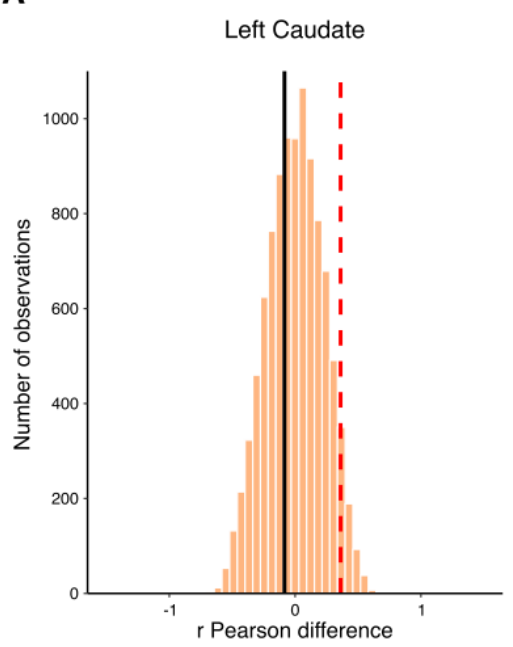

D

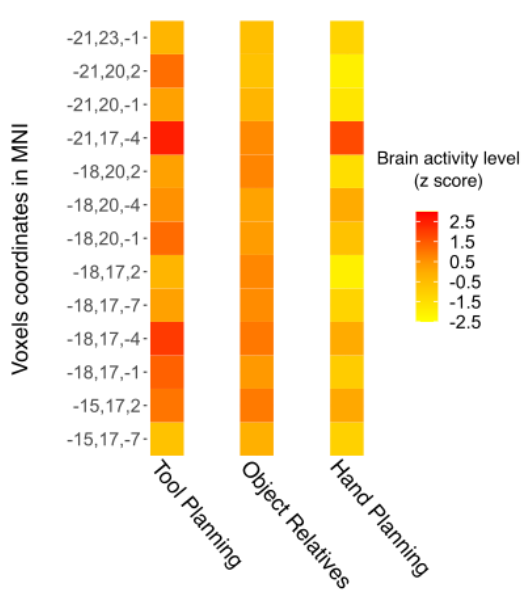

B

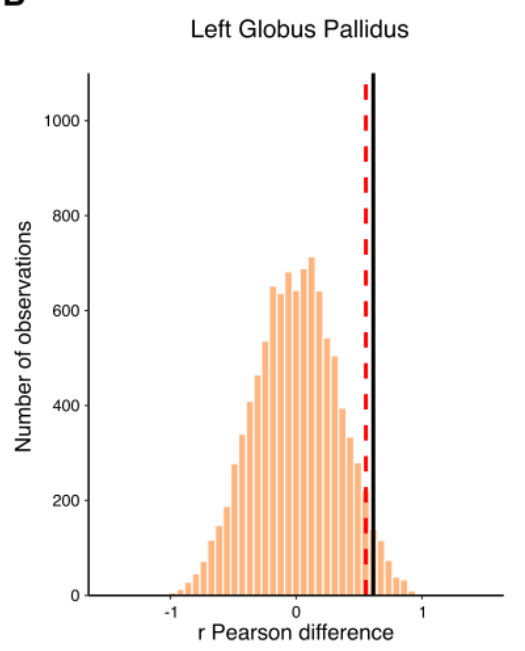

$\mathbf{E}$

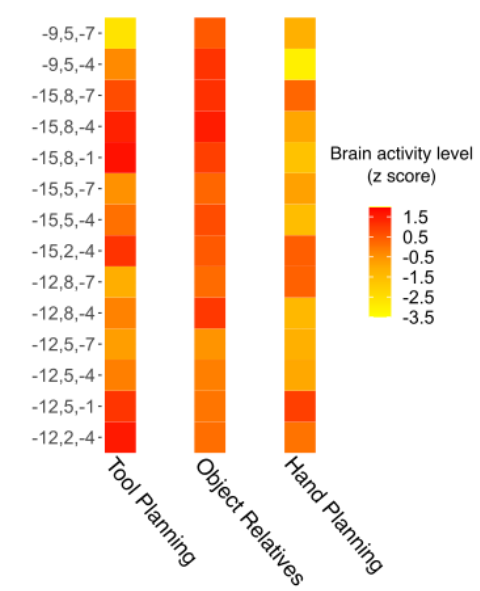

C

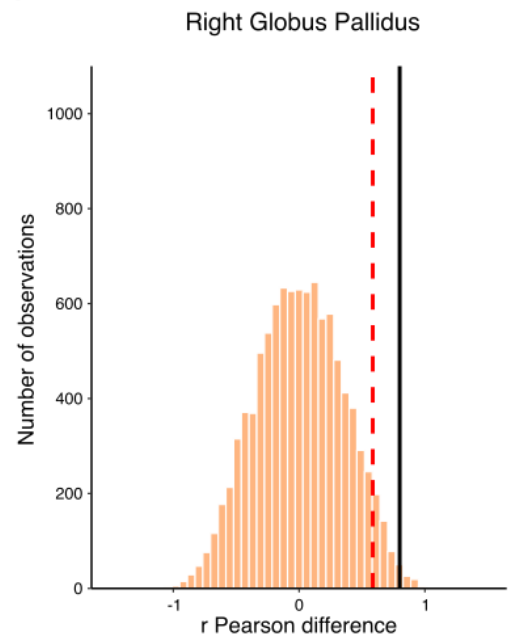

$\mathbf{F}$

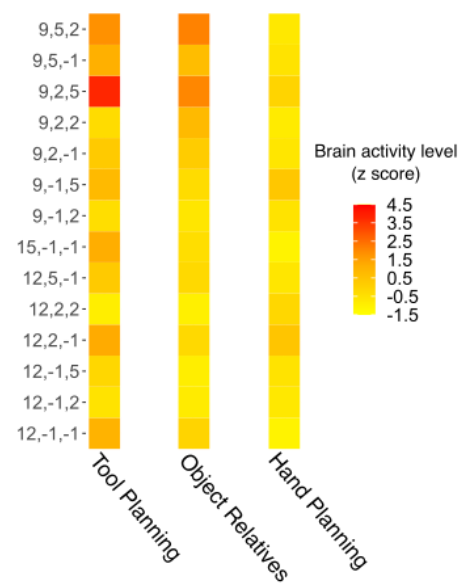

Fig. 2. Experiment 1: Functional link between tool-use planning and syntax in the basal ganglia. (A, B and C) Distribution, after 10,000 permutations, of differences of Pearson's $r$ computed for the correlations between patterns of brain activity for object relative clauses and those for motor planning of tool use and free hand separately, for the 1Cau (A), lGPi (B) and rGPi (C). Larger positive differences indicate stronger similarity between tool-use planning and object relative processing compared to free-hand planning and object relatives. The black line indicates the observed difference, and the red dotted line depicts the p-value threshold set at 0.05. (D, E and F) Spatial distribution of neural activity for tool-use planning, object relatives and free-hand planning in the basal ganglia. Each single colored square represents a single voxel for the lCau (D), lGPi (E) and rGPi (F). 


\section{Learning transfer from tool use to syntactic skills in language}

In Experiment 2 we tested whether tool-use training improves syntactic skills in language. We employed the same syntactic task employed in Experiment 1 to measure syntactic skills in 26 naive healthy adults before and after tool-use training (Fig. 3A). The specificity of tool use was controlled for by testing a distinct group $(\mathrm{N}=26)$ undergoing an identical training regime but with the free hand. A third passive control group $(\mathrm{N}=26)$ was also included to quantify potential test-retest effects: those participants were assessed in the same syntactic task before and after watching natural documentary videos for an equivalent amount of time as the two active groups engaged in motor training. The three groups were comparable in terms of relevant sociodemographic characteristics (Supplementary Text).

To assess the learning transfer to the syntactic task, we ensured that the participants significantly improved in their respective motor training (Fig. 3B; Supplementary Text). Then, we analyzed the impact of tool-use training, compared to both free-hand training and passive video watching, on performance in the syntactic task. We accounted for potential inter-individual differences in the initial syntactic level by including pre-test performance $\left(d^{\prime}\right)$ as a covariate in a 3-way Training $\times$ Time $\times$ Sentence ANCOVA run on RTs (see Supplementary Text for the corresponding ANOVA without the continuous factor in the model). The improvement in syntax depended on the type of training and the participants' initial level of syntactic performance $\left[\mathrm{F}_{(2,72)}=3.99 ; p=0.02 ; \eta_{G}^{2}=\right.$ 0.009]. Because the participants with lower scores before training are more prone to contextual improvements with task repetition (43), we specifically examined the training-dependent effects separating participants with low from those with high initial syntactic skills. We set a $d^{\prime}$ threshold based on the performance in the pre-test session, defined as the sample median minus one standard deviation (threshold $d^{\prime}>1.38$ ). Participants with lower syntactic skills (tool-use group: $\mathrm{N}=8$; freehand group: $\mathrm{N}=6$; video group: $\mathrm{N}=6$ ) significantly improved with all sentence structures at post- 
test and independent of training (Supplementary Text). This test-retest amelioration, potentially linked to more contextual aspects of the task such as motor and response selection, may hide potential selective effects of training. In the participants showing higher initial syntactic skills (tooluse group: $\mathrm{N}=18$, free-hand group: $\mathrm{N}=20$, video group: $\mathrm{N}=20$ ), tool-use training significantly improved syntactic performance compared to both free-hand training and passive video watching (significant Training $\times$ Time $\times$ Sentence interaction of the linear mixed model $(\mathrm{LMM}): \chi^{2}(4)=13.6$, $p=0.009 ;$ Fig. 3C). After tool use, the participants were significantly faster in correctly processing object relatives than before (pre-test RTs $=1892 \pm 137 \mathrm{~ms}$ vs. post-test $\mathrm{RTs}=1591 \pm 133 \mathrm{~ms}, p<$ 0.001, Tukey post hoc). In contrast, performance for object relatives did not significantly change for the two control groups (free hand: pre-test RTs $=1994 \pm 109$ ms vs. post-test RTs $=1910 \pm$ $109 \mathrm{~ms}, p=0.17$; video: pre-test $\mathrm{RTs}=2051 \pm 119 \mathrm{~ms}$ vs. post-test $\mathrm{RTs}=1940 \pm 128 \mathrm{~ms}, p=$ 0.10). Comprehension of object relatives was indistinguishable across the three groups before training $\left(p_{s}>0.63\right)$. A significant improvement was found for simpler syntactic structures, namely coordinated and subject relative clauses; nevertheless, these improvements were equivalent among the three groups (Fig. S3C and D, Supplementary Text). 
A
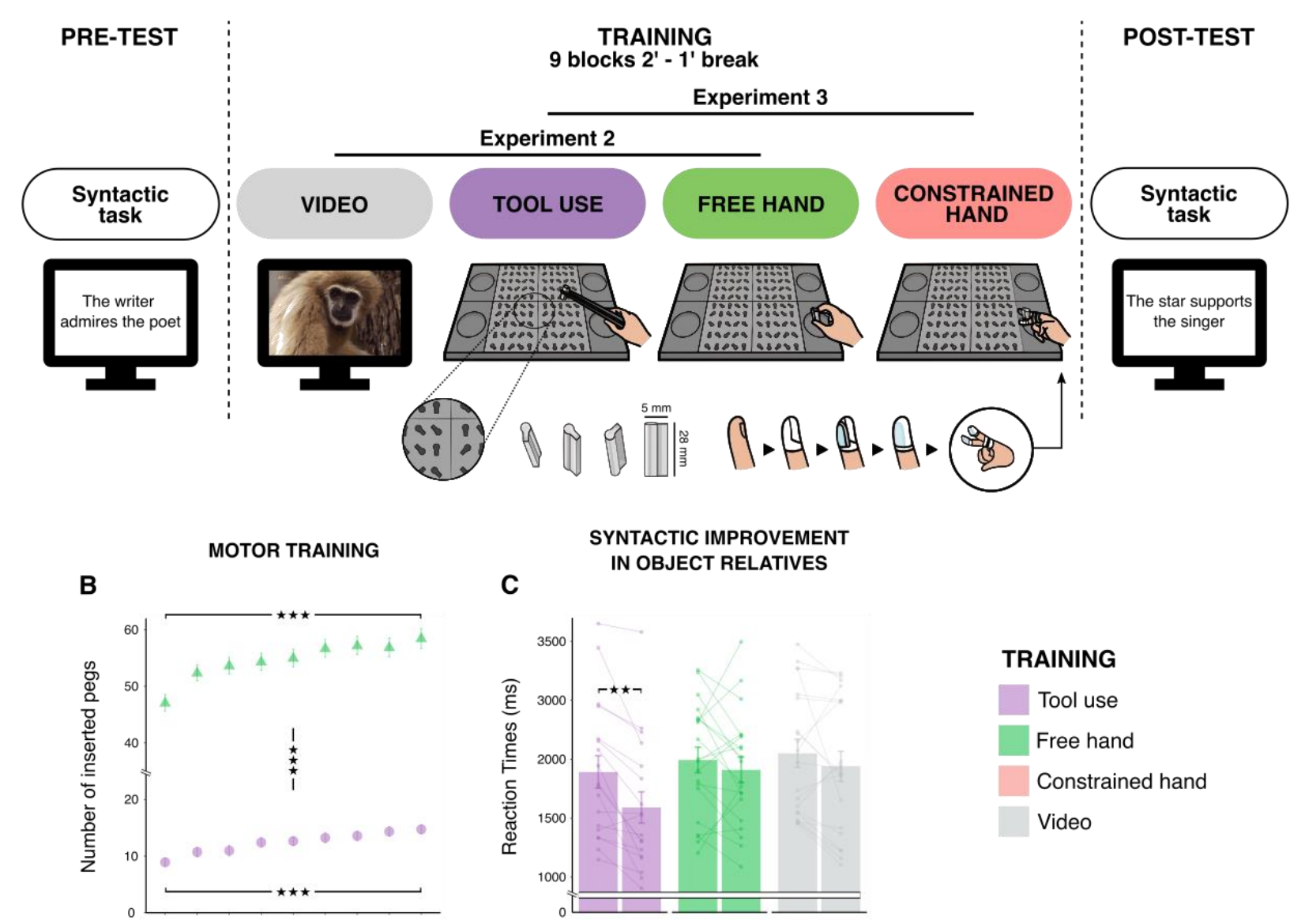

D

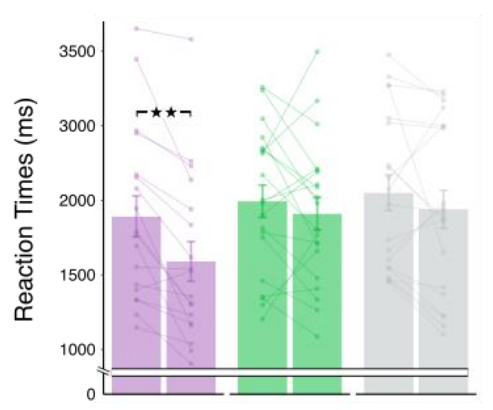

TRAINING

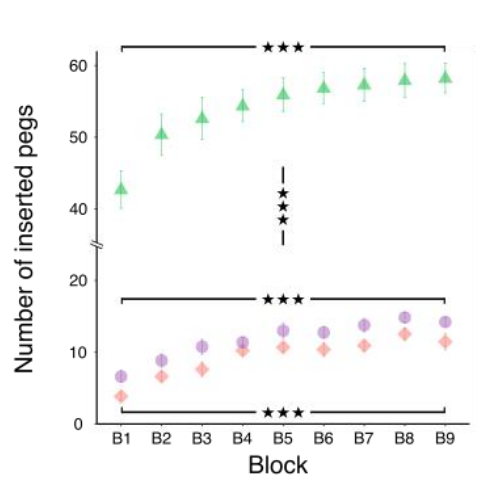

E

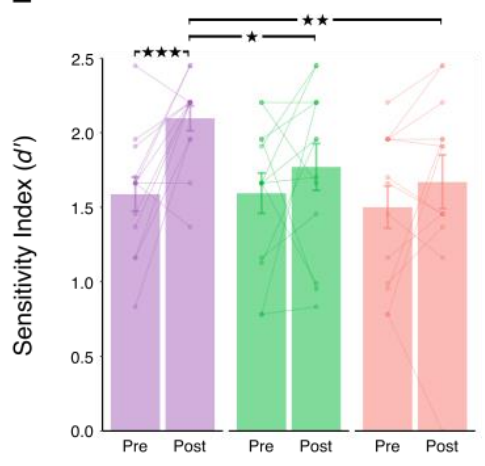

Tool use

Free hand

Constrained hand

Video

$\mathbf{F}$

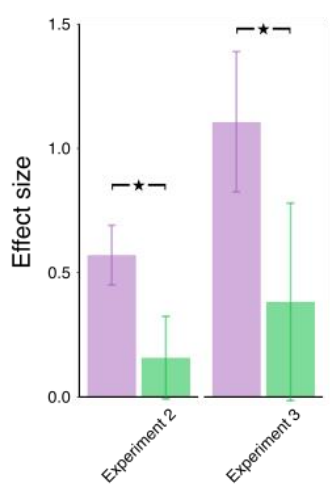

Fig. 3. Experiments 2 and 3: Cross-domain learning transfer from tool use to syntactic skills in language. (A) Timeline of training and syntactic pre- and post-tests. Different groups were trained either to use a tool (purple inset) or the free hand (green inset) to grab-and-enter key-shaped pegs into grooved holes, or they passively watched videos (gray inset). In Experiment 3, training difficulty was controlled with a further manual training condition (red inset) with increased sensorimotor constraints mimicking those present during tool use. (B) Motor improvement during tool- 
use (purple) and free-hand training (green) in Experiment 2. (C) In Experiment 2, participants with high initial syntactic skills improved for object relatives in the syntactic task after training with the tool (purple bars), but not after free-hand training (green bars) or passive video watching (gray bars). Connected dots across pre- and post-test represent individual data. (D) Motor improvement during tool-use (purple), free-hand (green) and constrained-hand training (red) in Experiment 3. (E) In Experiment 3, after tool use, the participants improved for object relatives in the syntactic task (purple bars), but not after training with the free hand (green bars) or with the hand mimicking similar sensorimotor constraints as the tool [red bars; significant Training $\times$ Time $\times$ Sentence interaction of the three-way repeated measure ANOVA (rmANOVA): $\left.\mathrm{F}_{(3.1,56.4)}=2.81 ; p=0.04 ; \eta_{G}^{2}=0.03\right]$. $(\mathbf{F})$ Effect size of the improvements in Experiments 2 and 3. 2-way Training $\times$ Experiment $\mathrm{rmANOVA}$ : significant main effect of Training $\left(\mathrm{F}_{(1,60)}=5.37 ; p=0.02\right.$; $\left.\eta_{G}{ }^{2}=0.082\right)$, non-significant effect of Experiment $\left(\mathrm{F}_{(1,60)}=2.8 ; p=0.11\right)$ nor any interaction $\left(\mathrm{F}_{(1,60)}=0.51 ; p=0.58\right)$. $* * * p<0.001 ; * * p<0.01 ; * p<0.05$. 
Training to use a tool improved syntactic abilities in a linguistic task. This effect depended on the individuals' initial syntactic level and was found in those participants showing better syntactic skills before training. To corroborate this finding, we performed an additional experiment (Experiment 3) in which we included a sample of 39 naive participants showing high syntactic scores in the pre-test session. As an independent criterion for inclusion in this new sample of participants, we adopted the threshold of syntactic performance before training identified in Experiment $2\left(d^{\prime}>\right.$ 1.38). To rule out the sensorimotor difficulty of the tool-use task as a factor contributing to learning transfer, we added a training condition where we reduced the degrees of freedom of free-hand movements to mimic those imposed by the tool. To rule out the sensorimotor difficulty of the tooluse task as a factor contributing to learning transfer, we introduced sensorimotor constraints in free-hand motor training (Supplementary Text). Tactile feedback was furthermore hampered (Fig. 3A). These changes were meant to provide a good simulation of pliers' sensorimotor constraints and difficulty. Two groups underwent either tool-use or free-hand training as in Experiment 2 to replicate our findings in an independent sample of participants with high syntactic skills. The third group was assigned to the control training condition with the constrained hand. Syntactic skills were measured in the three groups as in the previous assessments, before and after motor training.

First, we reaffirmed that tool-use training selectively improved comprehension of object relatives [Fig. 3E; pre-test $d^{\prime}=1.59 \pm 0.11$; post-test $d^{\prime}=2.1 \pm 0.08 ; p<0.001$, Tukey post hoc; significant Training $\times$ Time $\times$ Sentence interaction of the three-way repeated measure ANOVA (rmANOVA): $\left.\mathrm{F}_{(3.1,56.4)}=2.81 ; p=0.04 ; \eta G^{2}=0.03\right]$. Second, neither free-hand (pre-test $d^{\prime}=1.59 \pm 0.14$; posttest $d^{\prime}=1.77 \pm 0.16 ; p=0.10$ ) nor constrained-hand (pre-test $d^{\prime}=1.50 \pm 0.14 ;$ post-test $d^{\prime}=1.67$ $\pm 0.18 ; p=0.12$ ) training enhanced the performance for object relatives in a statistically significant way. After training, the tool-use group significantly outperformed both the free- $(p=0.04)$ and 
constrained-hand groups $(p=0.005)$ in the comprehension of object relatives. A difference between groups was observed for simpler syntactic structures (Fig. S3C and D, Supplementary Text). Furthermore, the magnitude of transfer was consistent with the syntactic improvement observed in Experiment 2 (Fig. 3F and Supplementary Text). 


\section{Learning transfer from syntactic training in language to tool use}

In line with the previous conclusion, shared neurofunctional resources between tool use and language also predict the reversed learning transfer: training syntactic processes with complex sentences should improve tool use. In the single-blind Experiment 4, we tested this prediction by measuring tool-use performance in 48 naive healthy adults before and after syntactic training in language (Fig. 4A). Participants were randomly assigned to train with either object or subject relative clauses. Before and after syntactic training, we measured the number of pegs entered with the tool in an adapted version of the motor task devised in the previous Experiments 2 and 3. The experimenter was blinded with respect to the type of syntactic training the participant was assigned to. The two groups were comparable in terms of relevant sociodemographic characteristics (Supplementary Text). Given the shared syntactic processes recruited by complex linguistic structures and tool use, we expected the participants to perform better with the tool after training with object rather than with subject relatives. 
A
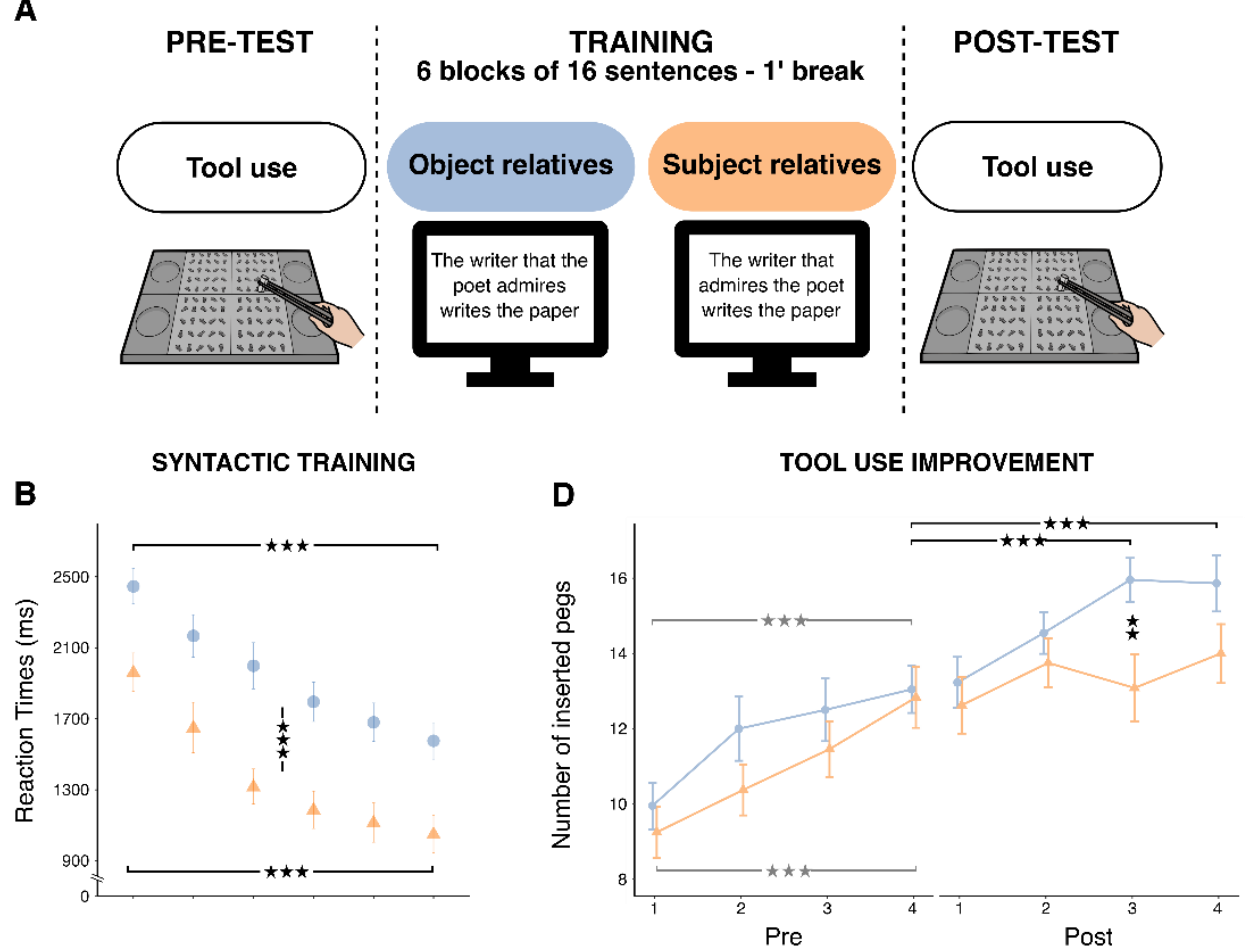

TRAINING

Object relatives

Subject relatives
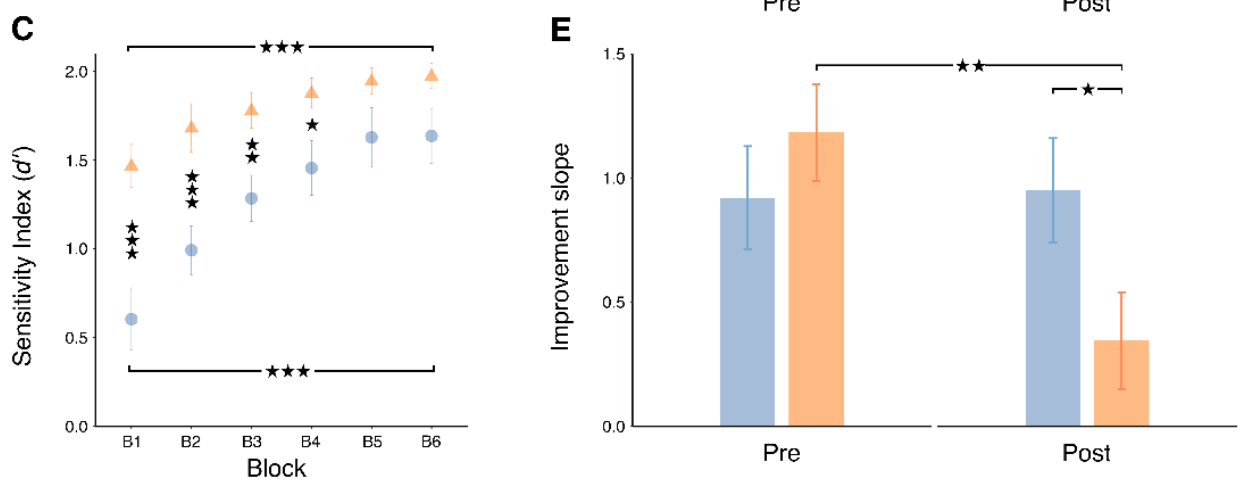

Fig. 4. Experiment 4: Cross-domain learning transfer from syntax in language to tool use. (A) Timeline of syntactic training and motor pre- and post-tests with the tool. Different groups were tested in entering pegs as fast as possible with the tool, before and after training either with object relative (blue) or subject relative clauses (orange). (B-C) Linguistic progress in RTs (B) and sensitivity ( $\left.d^{\prime}\right)$ (C) during syntactic training. (D) Motor performance, assessed with the number of pegs inserted with the tool equally improved in pre-test for the two groups. In post-test, only the group trained with object relatives (blue) kept improving, whereas the group trained with subject relatives (orange) did not (significant Training $\times$ Time $\times$ Sentence interaction of LMM: $\left.\chi^{2}{ }_{(3)}=9.88, p=0.01\right)$. $(\mathbf{E})$ Motor improvement quantified with the slope of the regression line along the progression from the $1^{\text {st }}$ to the $4^{\text {th }}$ block of tool use before (Pre) and after (Post) training with syntactic structures in language. $* * * p<0.001 ; * * p<0.01 ; * p<0.05$. 
Both groups improved in processing relative sentences during training (Fig. 4B-C). During pretest, the two groups improved similarly. In post-test, participants who trained with object relatives were able to enter significantly more pegs with the tool compared to those trained with subject relatives (significant Time $\times$ Block $\times$ Training interaction of the $\operatorname{LMM} \chi^{2}(3)=9.88, p=0.01$, Fig. 4D). Participants who trained with object relatives kept improving significantly with the tool (inserted pegs for block 4 pre-test $=12.9 \pm 0.6$ vs. blocks 3 post-test $=15.9 \pm 0.6$ and 4 post-test $=$ $15.7 \pm 0.7, p_{\mathrm{s}}<0.001$; and no difference compared to blocks 1 post-test $=13.0 \pm 0.7$ and 2 posttest $=14.3 \pm 0.6, p_{\mathrm{s}}>0.30 ;$ Fig. $\left.4 \mathrm{D}\right)$. In contrast, at no point after training with subject relatives, participants' motor performance differed from the best score before training (inserted pegs for block 4 pre-test $=12.8 \pm 0.8$ vs. blocks 1 post-test $=12.6 \pm 0.77$ or 2 post-test $=13.8 \pm 0.7$ or 3 post-test $=13.1 \pm 0.9$ or 4 post-test $\left.=14.0 \pm 0.8, p_{\mathrm{s}}>0.54\right)$. We calculated the slope of the regression line modeling individual motor performance along the blocks, before and after training separately (Supplementary Text). The slope was used to indicate motor improvement. A positive slope indicates that motor performance with the tool improved along the blocks, whereas a negative or horizontal slope stands for no improvement. A 2-way Training $\times$ Time rmANOVA revealed a significant interaction $\left[\mathrm{F}_{(1,46)}=4.57 ; p=0.03 ; \eta_{G}^{2}=0.05\right]$. The motor progression of the two groups was indistinguishable before training (subject relative group $\beta=1.18 \pm 0.20$ vs. object relative group $\beta=0.92 \pm 0.21, p=0.91)$. After training, the object relative group further improved $(\beta=$ $0.95 \pm 0.21$, as demonstrated by the significant difference between the observed slope and a horizontal line $\left(\mathrm{t}_{(23)}=4.47, p<0.001\right.$, Bonferroni-corrected, Cohen's $\left.\mathrm{d}=0.91\right)$ and by the comparison with the subject relative group $(\beta=0.35 \pm 0.20, p=0.03)$. After training, this latter group stopped improving ( $p=0.005$ compared to before training and $\mathrm{t}_{(23)}=1.76, p=0.18$ compared to a flat line). An additional Experiment 5 showed that the motor improvement observed after linguistic training 
with object relatives is specific to tool use. Indeed, after the object relative training, the participants inserted more pegs with the tool than with the constrained hand (Supplementary Text and Fig. S4).

\section{Discussion}

Our findings provide major new insights as to the neurocognitive links between tool use and syntax in language as well as to the principles underpinning cross-domain transfer. First, tool use and syntax rely on brain activity of anatomically overlapping neural networks, particularly in striatal structures (lCau) and the GPi. This overlap excluded working memory processes or unspecific difficulty as underlying components. Second, tool-use and syntax elicited similar activity patterns, consistent with common neural processes for both tasks.

These findings bolster the hypothesis of a supramodal syntactic function serving both action and language $(20,25)$. This is in line with the documented role of the dorsal striatum in processing complex hierarchical structures in both the motor (24) and linguistic domains (33). The dorsal striatum supports a wide range of procedural learning processes across several species (44-46) and tasks $(24,47)$. This part of the procedural system is involved in syntactic training $(47)$ and in the implementation of grammatical rules $(21,33)$. Furthermore, it acts as a parser of actions to chunk motor sequences $(24,48)$. Accurate and efficient tool use requires embedding an external object into the motor sequence, therefore relying more on the striatum than manual actions to parse the motor primitives (4). During dexterous tool use, hand movements integrate the functional structure of the tool in order to maintain an efficient interaction with the action target. The sensorimotor transformations imposed by the tool (28) constitute the additional level embedded to the manual motor program. Parsing and hierarchy handling also support syntactic comprehension of centerembedded object relatives $(21,33,34)$. These functional similarities are reflected by the neural overlap we revealed between tool use and syntax. The complexity of the hierarchies to be handled 
might however not be strictly commensurate. It is worth noting that this overlap was found in the BG but not within the left IFG. In keeping with its documented involvement in both tool use (35) and language (15), the lIFG was recruited by both functions, yet in two separately clustered regions. This occurred more posteriorly in the PMv for tool use and more anteriorly in Broca's area for syntactic comprehension, in accordance with the cytoarchitectonic and functional specialization of IIFG for motor and linguistic processing, respectively $(49,50)$.

These results explain the cross-domain learning transfer from tool use to syntactic skills in language and from linguistic syntax training to skilled tool use. Learning transfer arises provided that trained and untrained tasks rely on overlapping neural networks and shared cognitive processes (39). Transfer effects have been demonstrated from trained to untrained tasks belonging to the same domain: perception (51), motor (52) or cognitive control $(39,40,43)$. Crucially, we extended to different cognitive domains the principle of transfer that had so far been limited to a single domain $(39,40,51,52)$. Thus, the transfer holds true even when different cognitive domains, such as action and language, are involved. If trained and untrained tasks do not share common neurocognitive resources, transfer might be tempered or absent. Indeed, training with subject relative structures did not improve motor performance with the tool and free-hand training failed to induce benefits to syntax in the comprehension of complex structures. Furthermore, the benefits induced by tool use over language were not based on the mere additional sensorimotor complexity of the action executed with the tool compared to the free hand. After training with a hand configuration that involved similar sensorimotor constraints imposed by the tool, the participants did not show any advantage in processing complex syntactic structures compared to the participants training with the free hand. Crucially, the learning transfer between tool use and syntactic processes in language occurs bidirectionally. This finding unambiguously indicates that the two abilities rely on a common cognitive component, namely a supramodal syntax. It also suggests that the neural 
resources underlying the shared function can be similarly mobilized by either of the two abilities to improve the other.

What drives this cross-domain transfer? Pre-activation of common resources as well as fast plasticity within shared circuitries can underlie the reciprocal boosting of behavioral performance in tool use and syntax processing in language. Training may act as a functional prime for the subsequent task: training-dependent neuronal responses are elicited by tool use or sentence processing, thus yielding neuronal adaptation and more efficient activity (53). This in turn facilitates the subsequent behavioral performance for the untrained task relying on the same neural assemblies $(54$, 55). Alternatively, cross-domain transfer may rely on fast plastic changes within common circuitries. Short motor training (i.e., less than 2 hours) triggers rapid functional (44) as well as local structural changes, accompanied by improvements in behavioral performance $(56,57)$. The untrained task may benefit from such plastic changes and recruit new resources within the shared territories. These results raise the question of whether learning transfer can generalize to other linguistic tasks and of whether an optimal training duration could maximize the benefits. In the theoretical framework of the expansion-renormalization hypothesis (57), a thrilling opportunity would be to take advantage of the temporal dynamics of plastic changes, for instance, by testing syntax while new neural resources are locally and temporarily available during the course of tooluse training.

Overall, our findings reignite the hypothesis of a coevolution of tool use and language (58-60). Longstanding theories have claimed a motor origin of language during evolution $(25,61)$. The advent and refinement of tool use may have offered the neural niche for the coevolution of new cognitive skills serving both motor and communicative aims $(5,58,62,63)$. According to this account, the role of tool use has been twofold. On the one hand, the sophistication of tool use and 
tool making has put forward the need for cognitive functions to efficiently chunk, temporally parse and deal with hierarchies of sequences (60). On the other hand, tool use and tool making posed evolutionary pressure for communication, allowing better social transmission of knowledge (63). Functions responding to demands of the motor system would therefore have met communicative needs and progressively been exapted and recycled for language $(62,64)$. Such a coevolution scenario has involved a large brain network, from parietal $(58,60)$ to frontal regions $(60,65)$, and including the BG (66). Here, we provide central human evidence pointing to the BG in particular as the neural niche for a supramodal syntactic function serving both action and language. In conclusion, our findings show that the motor system can be exploited to promote other cognitive functions that partly share the same neurocognitive foundations. 


\section{References}

1. L. E. Miller, L. Montroni, E. Koun, R. Salemme, V. Hayward, A. Farnè, Sensing with tools extends somatosensory processing beyond the body. Nature. 561, 239-242 (2018).

2. S. H. Johnson-Frey, The neural bases of complex tool use in humans. Trends Cogn. Sci. 8, $71-78$ (2004).

3. P. M. Greenfield, Language, tools and brain: The ontogeny and phylogeny of hierarchically organized sequential behavior. Behav. Brain Sci. 14, 531-551 (1991).

4. K. Pastra, Y. Aloimonos, The minimalist grammar of action. Philos. Trans. R. Soc. B Biol. Sci. 367, 103-117 (2012).

5. J. Steele, P. F. Ferrari, L. Fogassi, From action to language: Comparative perspectives on primate tool use, gesture and the evolution of human language. Philos. Trans. R. Soc. B Biol. Sci. 367, 4-9 (2012).

6. M. Ben-Shachar, T. Hendler, I. Kahn, D. Ben-Bashat, Y. Grodzinsky, The Neural Reality of Syntactic Transformations: Evidence from Functional Magnetic Resonance Imaging. Psychol. Sci. 14, 433-440 (2003).

7. L. W. Barsalou, Grounded Cognition. Annu. Rev. Psychol. 59, 617-645 (2008).

8. F. Pulvermüller, L. Fadiga, Active perception: sensorimotor circuits as a cortical basis for language. Nat. Rev. Neurosci. 11, 351-360 (2010).

9. L. Craighero, L. Fadiga, G. Rizzolatti, C. Umiltà, Action for perception: A motor-visual attentional effect. J. Exp. Psychol. Hum. Percept. Perform. 25, 1673-1692 (1999).

10. C. Brozzoli, M. Ishihara, S. M. Göbel, R. Salemme, Y. Rossetti, A. Farne, Touch perception reveals the dominance of spatial over digital representation of numbers. Proc. Natl. 
Acad. Sci. U. S. A. 105, 5644-5648 (2008).

11. M. H. Fischer, A. D. Castel, M. D. Dodd, J. Pratt, Perceiving numbers causes spatial shifts of attention. Nat. Neurosci. 6, 555-556 (2003).

12. O. Hauk, I. Johnsrude, F. Pulvermüller, Somatotopic Representation of Action Words in Human Motor and Premotor Cortex. Neuron. 41, 301-307 (2004).

13. S. M. Wilson, A. P. Saygin, M. I. Sereno, M. Iacoboni, Listening to speech activates motor areas involved in speech production. Nat. Neurosci. 7, 701-702 (2004).

14. M. A. Just, P. A. Carpenter, T. A. Keller, W. F. Eddy, K. R. Thulborn, Brain activation modulated by sentence comprehension. Science. 274, 114-116 (1996).

15. M. Makuuchi, J. Bahlmann, A. Anwander, A. D. Friederici, Segregating the core computational faculty of human language from working memory. Proc. Natl. Acad. Sci. U. S. A. 106, 8362-8367 (2009).

16. A. Santi, Y. Grodzinsky, Working memory and syntax interact in Broca's area. Neuroimage. 37, 8-17 (2007).

17. P. Fazio, A. Cantagallo, L. Craighero, A. D’ausilio, A. C. Roy, T. Pozzo, F. Calzolari, E. Granieri, L. Fadiga, Encoding of human action in Broca's area. Brain. 132, 1980-1988 (2009).

18. A. C. Roy, A. Curie, T. Nazir, Y. Paulignan, V. des Portes, P. Fourneret, V. Deprez, Syntax at Hand: Common Syntactic Structures for Actions and Language. PLoS One. 8, 1-11 (2013).

19. F. Vargha-Khadem, K. Watkins, K. Alcock, P. Fletcher, R. Passingham, Praxic and non- 
verbal cognitive deficits in a large family with a genetically transmitted speech and language disorder. Proc. Natl. Acad. Sci. U. S. A. 92, 930-933 (1995).

20. F. Pulvermüller, The syntax of action. Trends Cogn. Sci. 18, 219-220 (2014).

21. M. T. Ullman, A neurocognitive perspective on language: The declarative/procedural model. Nat. Rev. Neurosci. 2, 717-726 (2001).

22. E. Koechlin, T. Jubault, Broca's Area and the Hierarchical Organization of Human Behavior. Neuron. 50, 963-974 (2006).

23. L. Maffongelli, E. Bartoli, D. Sammler, S. Kölsch, C. Campus, E. Olivier, L. Fadiga, A. D'Ausilio, Distinct brain signatures of content and structure violation during action observation. Neuropsychologia. 75, 30-39 (2015).

24. M. J. D. Martins, R. Bianco, D. Sammler, A. Villringer, Recursion in action : An fMRI study on the generation of new hierarchical levels in motor sequences. Hum. Brain Mapp. 40, 1-16 (2019).

25. A. C. Roy, M. A. Arbib, The syntactic motor system (John Benjamins Publishing Company, Amsterdam / Philadelphia, 2005).

26. L. Cardinali, F. Frassinetti, C. Brozzoli, C. Urquizar, A. C. Roy, A. Farnè, Tool-use induces morphological updating of the body schema. Curr. Biol. 19, 1157 (2009).

27. M. Jeannerod, Visuomotor channels: Their integration in goal-directed prehension. Hum. Mov. Sci. 18, 201-218 (1999).

28. L. Cardinali, C. Brozzoli, L. Finos, A. C. Roy, A. Farnè, The rules of tool incorporation : Tool morpho-functional \& sensori-motor constraints. Cognition. 149, 1-5 (2016).

29. Y. Itaguchi, K. Fukuzawa, Hand-use and tool-use in grasping control. Exp. Brain Res. 
232, 3613-3622 (2014).

30. C. Brozzoli, A. C. Roy, L. H. Lidborg, M. Lövdén, Language as a tool: Motor proficiency using a tool predicts individual linguistic abilities. Front. Psychol. 10, 1-9 (2019).

31. M. P. Alexander, M. A. Naeser, C. L. Palumbo, Correlations of subcortical CT lesion sites and aphasia profiles. Brain. 110, 961-988 (1987).

32. M. Grossman, A. Cooke, C. DeVita, C. Lee, D. Alsop, J. Detre, J. Gee, W. Chen, M. B. Stern, H. I. Hurtig, Grammatical and resource components of sentence processing in Parkinson's disease: An fMRI study. Neurology. 60, 775-781 (2003).

33. A. Moro, M. Tettamanti, D. Perani, C. Donati, S. F. Cappa, F. Fazio, Syntax and the brain: Disentangling grammar by selective anomalies. Neuroimage. 13, 110-118 (2001).

34. M. Teichmann, C. Rosso, J. B. Martini, I. Bloch, P. Brugières, H. Duffau, S. Lehéricy, A. C. Bachoud-Lévi, A cortical-subcortical syntax pathway linking Broca's area and the striatum. Hum. Brain Mapp. 36, 2270-2283 (2015).

35. M.-L. Brandi, A. Wohlschläger, C. Sorg, J. Hermsdörfer, The Neural Correlates of Planning and Executing Actual Tool Use. J. Neurosci. 34, 13183-13194 (2014).

36. F. E. Garcea, L. J. Buxbaum, Gesturing tool use and tool transport actions modulates inferior parietal functional connectivity with the dorsal and ventral object processing pathways. Hum. Brain Mapp. 40, 2867-2883 (2019).

37. S. H. Johnson-Frey, R. Newman-Norlund, S. T. Grafton, A distributed left hemisphere network active during planning of everyday tool use skills. Cereb. Cortex. 15, 681-695 (2005).

38. S. Obayashi, T. Suhara, K. Kawabe, T. Okauchi, J. Maeda, Functional Brain Mapping of 
Monkey Tool Use. Neuroimage. 14, 853-861 (2001).

39. E. Dahlin, A. S. Neely, A. Larsson, L. Bäckman, Transfer of Learning After Updating Training Mediated by the Striatum. Science. 320, 1510-1512 (2008).

40. S. M. Jaeggi, M. Buschkuehl, J. Jonides, W. J. Perrig, Improving fluid intelligence with training on working memory. Proc. Natl. Acad. Sci. U. S. A. 105, 6829-6833 (2008).

41. J. Diedrichsen, N. Kriegeskorte, Representational models: A common framework for understanding encoding, pattern-component, and representational-similarity analysis. PLoS Comput. Biol. 13, 1-33 (2017).

42. M. V Peelen, A. J. Wiggett, P. E. Downing, Patterns of fMRI activity dissociate overlapping functional brain areas that respond to biological motion. Neuron. 49, 815-822 (2006).

43. S. M. Jaeggi, M. Buschkuehl, J. Jonides, P. Shah, Short- and long-term benefits of cognitive training. Proc. Natl. Acad. Sci. U. S. A. 108, 10081-10086 (2011).

44. S. Lehéricy, H. Benali, P.-F. Van De Moortele, M. Pélégrini-issac, T. Waechter, K. Ugurbil, J. Doyon, Distinct basal ganglia territories are engaged in early. Proc. Natl. Acad. Sci. 102, 12566-12571 (2005).

45. H. Makino, E. J. Hwang, N. G. Hedrick, T. Komiyama, Circuit Mechanisms of Sensorimotor Learning. Neuron. 92, 705-721 (2016).

46. H. H. Yin, S. P. Mulcare, M. R. F. Hilário, E. Clouse, T. Holloway, M. I. Davis, A. C. Hansson, D. M. Lovinger, R. M. Costa, Dynamic reorganization of striatal circuits during the acquisition and consolidation of a skill. Nat. Neurosci. 12, 333-341 (2009).

47. K. M. Tagarelli, K. F. Shattuck, P. E. Turkeltaub, M. T. Ullman, Language learning in the 
adult brain: A neuroanatomical meta-analysis of lexical and grammatical learning. Neuroimage. 193, 178-200 (2019).

48. A. M. Graybiel, S. T. Grafton, The striatum: Where skills and habits meet. Cold Spring Harb. Perspect. Biol. 7, 1-14 (2015).

49. K. Amunts, M. Lenzen, A. D. Friederici, A. Schleicher, P. Morosan, N. Palomero-Gallagher, K. Zilles, Broca's region: Novel organizational principles and Multiple Receptor Mapping. PLoS Biol. 8, 1-16 (2010).

50. G. Papitto, A. D. Friederici, E. Zaccarella, The topographical organization of motor processing: An ALE meta-analysis on six action domains and the relevance of Broca's region. Neuroimage. 206, 1-15 (2020).

51. D. Muret, H. R. Dinse, S. Macchione, C. Urquizar, A. Farnè, K. T. Reilly, Touch improvement at the hand transfers to the face. Curr. Biol. 24, R736-R737 (2014).

52. S. Vyas, N. Even-Chen, S. D. Stavisky, S. I. Ryu, P. Nuyujukian, K. V. Shenoy, Neural Population Dynamics Underlying Motor Learning Transfer. Neuron. 97, 1177-1186 (2018).

53. K. Grill-Spector, R. Henson, A. Martin, Repetition and the brain: Neural models of stimulus-specific effects. Trends Cogn. Sci. 10, 14-23 (2006).

54. V. Boulenger, A. C. Roy, Y. Paulignan, V. Deprez, M. Jeannerod, T. A. Nazir, Cross-talk between Language Processes and Overt Motor Behavior in the First $200 \mathrm{msec}$ of Processing. J. Cogn. Neurosci. 18, 1607-1615 (2006).

55. R. N. A. Henson, Neuroimaging studies of priming. Prog. Neurobiol. 70, 53-81 (2003).

56. T. Xu, X. Yu, A. J. Perlik, W. F. Tobin, J. A. Zweig, K. Tennant, T. Jones, Y. Zuo, Rapid 
formation and selective stabilization of synapses for enduring motor memories. Nature. 462, 915-919 (2009).

57. E. Wenger, C. Brozzoli, U. Lindenberger, M. Lövdén, Expansion and Renormalization of Human Brain Structure During Skill Acquisition. Trends Cogn. Sci. 21, 930-939 (2017).

58. A. Iriki, M. Taoka, Triadic (ecological, neural, cognitive) niche construction: A scenario of human brain evolution extrapolating tool use and language from the control of reaching actions. Philos. Trans. R. Soc. B Biol. Sci. 367, 10-23 (2012).

59. M. S. Ponce de León, T. Bienvenu, A. Marom, S. Engel, P. Tafforeau, J. L. Alatorre Warren, D. Lordkipanidze, I. Kurniawan, D. B. Murti, R. A. Suriyanto, T. Koesbardiati, C. P. E. Zollikofer, The primitive brain of early Homo . Science. 372, 165-171 (2021).

60. D. Stout, T. Chaminade, Stone tools, language and the brain in human evolution. Philos. Trans. R. Soc. Lond. B. Biol. Sci. 367, 75-87 (2012).

61. G. Rizzolatti, M. A. Arbib, Language within our grasp. Trends Cogn. Sci. 2236, 16671669 (1998).

62. S. Dehaene, L. Cohen, Cultural recycling of cortical maps. Neuron. 56, 384-398 (2007).

63. T. J. H. Morgan, N. T. Uomini, L. E. Rendell, L. Chouinard-Thuly, S. E. Street, H. M. Lewis, C. P. Cross, C. Evans, R. Kearney, I. De La Torre, A. Whiten, K. N. Laland, Experimental evidence for the co-evolution of hominin tool-making teaching and language. Nat. Commun. 6, 4-11 (2015).

64. M. L. Anderson, Précis of after Phrenology: Neural Reuse and the Interactive Brain. Behav. Brain Sci. 39 (2015).

65. W. D. Hopkins, A. Meguerditchian, O. Coulon, M. Misiura, S. Pope, M. C. Mareno, S. J. 
Schapiro, Motor skill for tool-use is associated with asymmetries in Broca's area and the motor hand area of the precentral gyrus in chimpanzees (Pan troglodytes). Behav. Brain Res. 318, 71-81 (2017).

66. P. Lieberman, The evolution of language and thought. J. Anthropol. Sci. 94, 127-146 (2016).

67. R. C. Oldfield, The assessment and analysis of handedness: The Edinburgh inventory. Neuropsychologia. 9, 97-113 (1971).

68. B. New, C. Pallier, M. Brysbaert, L. Ferrand, Lexique 2: A new French lexical database. Behav. Res. Methods, Instruments, Comput. 36, 516-524 (2004).

69. J. R. Reynolds, R. West, T. Braver, Distinct neural circuits support transient and sustained processes in prospective memory and working memory. Cereb. Cortex. 19, 1208-1221 (2009).

70. L. A. Jones, S. J. Lederman, Human Hand Function (Oxford University Press, Oxford New York, 2006).

71. T. Nichols, M. Brett, J. Andersson, T. Wager, J. B. Poline, Valid conjunction inference with the minimum statistic. Neuroimage. 25, 653-660 (2005).

72. N. N. Oosterhof, A. C. Connolly, J. V Haxby, CoSMoMVPA: Multi-modal multivariate pattern analysis of neuroimaging data in matlab/GNU octave. Front. Neuroinform. 10, 127 (2016).

73. H. Singmann, B. Bolker, J. Westfall, F. Aust, S. M. Ben-Shachar, afex: Analysis of Factorial Experiments. R package version 0.27-2. https://CRAN.R-project.org/package=afex (2020). 
74. L. L. Chao, J. V. Haxby, A. Martin, Attribute-based neural substrates in temporal cortex for perceiving and knowing about objects. Nat. Neurosci. 2, 913-919 (1999).

75. C. Cavina-Pratesi, J. D. Connolly, S. Monaco, T. D. Figley, A. D. Milner, T. Schenk, J. C. Culham, Human neuroimaging reveals the subcomponents of grasping, reaching and pointing actions. Cortex. 98, 128-148 (2018). 
Acknowledgments: We thank Elisabeth Wenger, Alessandro Farnè and Emiliano Macaluso for their precious advice; Elvio Blini for the support to parts of the statistical analyses; Franck Lamberton and Danielle Ibarrola for helping with fMRI acquisitions and settings; François Leconte for graphic contribution to the figures; Frédéric Volland for the realization of parts of the setup; the research assistants for helping with the acquisitions; Quercetti for kindly providing the peg-board games employed in the scanner; Sonia Alouche, Jean-Louis Borach and Célia Farge for the administrative support to the project. Funding: CB is supported by Swedish Research Council grant (2015-01717) and ANR-JC (ANR-16-CE28-0008-01). ML by Swedish Research Council (201801047). ACR by ANR (ANR-16-CE28-0015). ACR and VB by LabEx ASLAN (ANR-10-LABX0081; ANR-11-IDEX-0007). Author contributions: Conceptualization and methodology: S.T., M.L., V.B., A.C.R., and C.B.; Software, validation and formal analyses: S.T., R.S., E.K., C.B.; Material and set-up: S.T., R.S. and E.K.; Investigation and data curation: S.T., R.P., A.M.G., and C.B; Original draft preparation and visualization: S.T. and C.B.; Writing - review and editing: all authors. Competing interests: The authors declare no competing interests. Data and materials availability: Data, materials and codes for analyses are available at https://osf.io/mw3pf/.

\section{Supplementary Materials:}

Figures S1-S4; Tables S1-S3; Movies S1-S2 


\section{Science AlAAAS}

\section{Supplementary Materials for}

Tool use and language share syntactic processes and neural patterns in the basal ganglia

Simon Thibault", Raphaël Py, Angelo Mattia Gervasi, Romeo Salemme, Eric Koun, Martin Lövden, Véronique Boulenger ${ }^{\dagger}$, Alice C. Roy ${ }^{\dagger}$, Claudio Brozzoli ${ }^{*}$

*Correspondence to: simon.thibault@inserm.fr , claudio.brozzoli@inserm.fr

$\dagger$ Equal contributions.

This PDF file includes:

Materials and Methods

Supplementary Text

Figs. S1 to S4

Tables S1 to S3

Captions for Movies S1 to S2

Other Supplementary Materials for this manuscript include the following:

Movies S1 to S2 


\section{Materials and Methods}

\section{Participants}

A total of 244 participants were included in the study, which consists of five different experiments. None of the participants took part in more than one experiment. All participants were healthy righthanded French native speakers with normal or corrected-to-normal vision and no known motor, linguistic or neurological disorders. They gave their written informed consent prior to experiment acquisition. All procedures agreed with the Helsinki declaration and were approved by an ethical committee (46/17_2, OUEST IV).

\section{Experiment 1}

The fMRI acquisition in Experiment 1 included 24 participants who received a compensation of 110 euros. Four participants were excluded: two did not fulfill the a-priori-set familiarization performance requirements before any neuroimaging acquisition, one dropped out after the inclusion phase and one was removed from analyses due to substantial head movements (several runs with movements above $1.5 \mathrm{~mm}$ ). Thus, we analyzed 20 participants with the following sociodemographic characteristics and manual preference: 10 males and 10 females; mean age \pm SD: $24 \pm 4$ years old; mean score on the Edinburgh handedness inventory (67): $0.93 \pm 0.09$; higher education level, namely the number of years of education after a high school degree: $3 \pm 2$ years.

\section{Experiment 2}

In this experiment, 85 participants were included and received a compensation of 10 euros. Six participants performed the experiment but were excluded from analysis due to performance below chance level in at least one sentence condition, and one for having incorrectly used the right hand to deliver the button press. In total, 78 participants were entered into the analyses. They had the following characteristics: 27 males and 51 females; mean age: $23 \pm 3$ years old; higher education level: $4 \pm 1$ years, mean Edinburgh score: $0.9 \pm 0.12$.

\section{Experiment 3}

Experiment 3 included 46 participants who were paid 15 euros for their participation. The threshold of $d^{\prime}>1.38$ in pre-test, as identified in Experiment 2, was applied as an independent criterion for inclusion. Data from two participants were excluded due to error in sensitivity index calculation at pre-test, four other were excluded for sensitivity index below the threshold, and one other for 
having inverted the response keys during the task. Overall, data from 39 participants were analyzed. The group presented the following characteristics: 11 males and 28 females; mean age: 24 \pm 5 years old; mean Edinburgh score: $0.87 \pm 0.11$; higher education level: $3 \pm 1$ years.

\section{Experiment 4}

In this experiment, 48 participants were recruited and were paid 40 euros for their participation. The group presented the following characteristics: 24 males and 24 females; mean age: $27 \pm 5$ years old; mean Edinburgh score: $0.88 \pm 0.1$; higher education level: $5 \pm 2$ years.

\section{Experiment 5}

In this experiment, 41 participants were recruited and were paid 45 euros for their participation. Data from one participant were excluded due to a technical problem. Overall, data from 40 participants were analyzed. The group presented the following characteristics: 13 males and 27 females; mean age: $27 \pm 6$ years old; mean Edinburgh score: $0.92 \pm 0.1$; higher education level: $4 \pm 2$ years.

\section{$\underline{\text { Tasks }}$}

\section{Syntactic task}

A two-alternative forced choice task (2-AFC) allowed to assess syntactic abilities to process sentences composed of the same content words but featuring different structures: coordinated, centerembedded subject relative, or center-embedded object relative clauses. Table 1A offers examples for each condition, and the entire material is available in Table S3. The content words included in the sentences were controlled for word frequency and number of syllables from the Lexique 3.80 database (68), as well as for the gender of the subjects and objects of the described action. Each sentence was presented using rapid serial visual presentation (RSVP) in six consecutive segments displayed in the middle of the screen for $500 \mathrm{~ms}$, interspaced by a $100-\mathrm{ms}$ blank screen. This presentation mode was chosen based on previous work using comprehension tasks of visually presented sentences $(14,15)$ to avoid idiosyncratic reading strategies and/or saccadic eye movements. After presentation of the final segment of each sentence, a test affirmation was displayed on the screen (Table 1B) until the participant answered or for a maximum of $5 \mathrm{~s}$. The participants were instructed to respond as quickly and correctly as possible via a button press with their left hand as to whether the affirmation was TRUE or FALSE with respect to the preceding sentence. The button-response association was counterbalanced across the participants. 
In the fMRI Experiment 1, a total of 48 trials were presented in a randomized order during the run and consisted of the presentation of sentences featuring the three different syntactic structures in equal proportion $(\mathrm{N}=16$ each): coordinated, subject relative and object relative clauses. The intertrial period was jittered between 5 and $7 \mathrm{~s}$. The sentences were visible through the mirror oriented towards the screen placed on the back of the scanner bore.

For behavioral Experiments 2 and 3, outside of the scanner, the total number of trials in each experiment was 72, with 24 trials per each syntactic structure. The intertrial period was jittered between 2.5 and $3.5 \mathrm{~s}$, and a 1-minute rest period was added halfway through the block. The scripts controlling the presentation and recording participants' answers were programmed in Psychtoolbox (PTB-3) running on MATLAB (Mathworks, Natick, USA).

\section{Verbal working memory task}

In Experiment 1, to disentangle the potential contribution of working memory processes to syntactic brain activity, the participants also performed an $n$-back task with four words of equal length and frequency (Lexique 3.80). Two 1-back and two 3-back runs were acquired. Words were presented with a RSVP in the center of the screen for $1500 \mathrm{~ms}$. The intertrial period varied between $1 \mathrm{~s}$ and $4 \mathrm{~s}$ at 1 -s steps in line with effective published protocols (69). The participants were required to press a button with their left index finger if a target word appearing on the screen matched the preceding word (1-back) or the one presented two steps earlier (3-back). Each run included 76 trials with 19 targets. The word stream was made visible using the same apparatus as for the syntax task. Similar to the syntax task, the verbal working memory task scripts were programmed onto Psychtoolbox (PTB-3) running on MATLAB (Mathworks, Natick, USA).

\section{fMRI tool-use task}

The participants were required to use a pair of 30-cm-long pliers held with their right hand to move a peg (Fig. 1D) on a plastic board (Quercetti, Torino, Italy) between two fixed visual landmarks separated by an approximate 9-cm distance (see Movies S1 and S2). To begin a trial, the participants, in a resting position, had to wait for a pure tone signal delivered through an MRI compatible device aimed to actively reduce MRI noise (Optoacoustics OptoACTIVE-two way noise cancellation communication system, Mazor, Israel). A single presentation of the pure tone warned the participant to prepare to move, and the double presentation of this tone presented $4 \mathrm{~s}$ later indicated the Go for the action. This sequence was repeated twice to pace the requested movements: grasping 
the peg to displace it from the first to the second location and then grasping it again to move it back to its initial position. The whole sequence (4-s planning - 4-s execution - 4-s planning - 4-s execution - 10-s rest) was repeated 15 times in a single run. If a peg fell, the participant had to indicate the missed sequence by pressing a button with the left index finger and then grab a new peg from the left side of the plastic board. The few missed trials (lower than $0.5 \%$ ) were modeled separately. In a distinct run, the same task was performed with the free hand and served as a control to highlight the tool-specific neural network. The motor task device was placed in front of the participant at a reachable distance and made visible with a double mirror mounted onto the head coil. The participants' right upper arm was strapped to the trunk to limit elbow and shoulder movements. The scripts controlling the audio sequence of instructions in the scanner were delivered with Presentation software (NBS, Berkeley, USA).

\section{Motor training}

Tool-use training was similar to the tool-use task design for fMRI acquisitions. As previously described, the participants were required to insert pegs on a board using the same 30-cm-long pliers with their right hand. Training was performed with grooved, key-shaped pegs (Grooved Pegboard Test, Lafayette instruments, Model $32025^{2}$ ), which need to be meticulously oriented to fit the target hole. In total, four boards were placed in front of the participant with a plastic box containing the pegs located in front of the boards. The training consisted of inserting as many pegs as possible during 9 blocks of 2 minutes, interspersed with 1-minute rest. The motor performance was indexed by the total number of correctly inserted pegs. A between-subjects design across Experiments 2 and 3 tested the hypothesis that syntactic skills improved in the group of participants training with the tool compared to three control groups of participants. One control condition consisted of the same motor training but performed with the right bare hand (i.e., free-hand training) to control for unspecific effects of motor training over the untrained task (Experiments 2 and 3). The second control condition was a passive control for potential test-retest effects in the absence of any motor task. The participants assigned to this condition were required to watch soundless nature documentary videos (Experiment 2) following the same procedure as for both tool-use and free-hand motor training, namely 9 blocks of 2-minute videos interspersed with 1-minute rest (with a gray screen).

In Experiment 3, we replicated the acquisition with tool-use and free-hand training in new samples of participants, and added a third training condition to control for the sensorimotor difficulty of 
tool-use training. From a sensorimotor point of view, training with the tool was more difficult than free-hand training. Indeed, the tool reduces sensory feedback while handling the pegs. In addition, the motor constraints introduced by the tool hinder the potential easing contribution of the fingers available in the free-hand condition. Proof of the difficulty is the reduced number of pegs inserted by the participants training with the tool compared with the free hand in Experiment 2. To rule out the sensorimotor difficulty of the task as a factor contributing to learning transfer, we introduced additional sensorimotor constraints in the free-hand motor training to mimic those imposed by the tool. To this end, we instructed participants to grab and enter pegs using a pinch formed by their middle and index fingers. Beside the fingers employed to carry out the grip, two further changes were applied to reduce the degrees of freedom of manual movements towards those characterizing tool use. The degrees of freedom of the hand are estimated to exceed 20 (approximately 27 (70)): 4 for each finger except for the thumb ( 3 for flexion/extension and 1 for abduction/adduction); 5 for the thumb; and 6 for translation and rotation of the wrist. The degrees of freedom of tool use on the other hand approximate 7: 1 for abduction/adduction of pliers and 6 for wrist translation and rotation. Participants were asked to cross their index and middle fingers (index underneath) which were strapped together at the level of the proximal phalanx with dermocompatible tape and velcro. This prevented independent flexion or extension of the fingers ( -3 degrees of freedom approximately). This constraint resulted in a pliers-like configuration with the middle finger's inner side over the index finger nail, and were explicitly required to use these two fingers without the contribution of the thumb, the ring and little fingers (approximately 13 fewer degrees of freedom). Second, we hindered somatosensory feedback of participants' index and middle fingers with a layer of flat velcro between two layers of dermocompatible tape attached on each fingertip (Fig. 3A, red inset). This constrained hand condition ensured lack of direct sensory feedback, as experienced with the tool, as well as the inability to adjust peg orientation by simply slipping it between the middle and index fingers (therefore reducing the impact of the 6 degrees of freedom of flexion/extension). Accordingly, the participants had to rely more on wrist rotations to insert the pegs, with hindered sensory feedback, similar to the experience during tool use.

\section{Motor test}

The motor training was adjusted into a motor test to enable the measurement of a change in tooluse motor performance following syntactic training in Experiment 4. Participants were asked to use the tool with their right hand to enter as many pegs as possible during 4 blocks of 2 minutes, 
interspersed with 1-minute rest. This test was performed before and after linguistic training. The motor performance was indexed by the number of correctly inserted pegs per block. In Experiment 5 , a similar adjustment allowed to measure the motor performance with the constrained hand before and after linguistic training, in comparison to changes in tool use performance. For the constrained-hand condition, the participants' right hand featured the same constraints as described above for the constrained-hand training. To avoid any difference in the motor baseline between the tool-use and constrained-hand groups and therefore ensure the reliability of the comparison, participants could start to train with object relatives only after they reached a threshold of 8 pegs inserted in a block of two minutes. Such a threshold was based on the data of Experiment 3 showing similar performance for the tool-use and the constrained-hand tasks around the 4th block of the motor training (on average 10.8 pegs with a standard deviation of 2.4 pegs). The 2-minute block was repeated up to a limit of 6 blocks to reach the 8-pegs criterion. All participants reached this threshold before the sixth block (i.e. 1.6 blocks on average and 4 blocks maximum for the slowest participants). Once ensured a comparable level of pre-test performance, after the linguistic training, the participants performed 4 blocks of 2 minutes with 1-minute rest (post-test).

\section{Syntactic training}

In order to evaluate the effect of linguistic training on tool use in Experiment 4, the syntax task employed in Experiments 1 to 3 was adapted into a training protocol. Training was composed of 96 trials, split in 6 blocks of 16 sentences each. Blocks were interspersed with 1-minute rest periods. Participants were allowed a maximum of 5 seconds to respond to the test affirmation presented after each sentence by pressing one of two buttons with their left hand. Once they answered, a coherent feedback appeared for $1.5 \mathrm{~s}$ : a green « $\sqrt{ } »$ or a red «X $\mathrm{X}$ for correct or incorrect answers respectively. At the end of each block, the accuracy and average reaction time were displayed so that participants were made aware of their progress in performance (as in the motor training in Experiments 2 and 3). Using a single-blind procedure, participants were assigned to one of two groups: one was trained with subject relative clauses and the other with object relative clauses. Participants were reminded to try to improve their accuracy and reaction time performance at each block. Task scripts were programmed onto Psychtoolbox (PTB-3) running on MATLAB (Mathworks, Natick, USA). In Experiment 5, all participants underwent the same training with only object relatives, following the same procedure as for Experiment 4. 
$\underline{\text { Procedures }}$

\section{Experiment 1: fMRI}

The experiment consisted of an inclusion session to familiarize participants with the tasks and check that the individual level of performance met the inclusion criteria. Short versions of the syntactic, verbal working memory and motor tasks were conducted. The requirements to be included in the fMRI session were at least 16 successes in the syntactic task (over 24 trials), with 4 successes for the most complex condition (object relative clauses, over 8 trials). For the 3-back task, the participants were required to correctly identify at least 3 targets out of 8 among a total of 32 trials, without performing more than 6 false alarms. For the 1-back task, one block of 16 trials was performed, with the same requirements. This was meant to maximize the number of correct and analyzable trials in each task during the neuroimaging acquisition. The motor task for inclusion comprised two blocks of tool-use movements and two blocks of free-hand movements. In each block, the participants were instructed to insert ten pegs as quickly as possible on the two first lines of the Grooved Pegboard test. To be included in the experiment, they had to perform the two tooluse blocks in less than 5 minutes on average and the two free-hand blocks with an average of less than 1 minute. After inclusion, the participants performed two different fMRI sessions separated by two days. Each session consisted of an anatomical acquisition (T1-weighted), followed by motor (tool use and free hand) and linguistic runs in a counterbalanced order. The participants were tested in the working memory and syntactic tasks during the same session. Two additional linguistic tasks assessing phonological and semantic processing were performed in the other session; these results will be presented in a separate report. The session order was counterbalanced across participants.

Functional and anatomical MRIs were acquired with a Siemens Prisma 3T scanner (Siemens Medical systems, Erlangen, Germany) with a gradient echo EPI sequence, with TE $=30 \mathrm{~ms}$ and $\mathrm{TR}=$ $2400 \mathrm{~ms}$. Volumes were acquired with 44 interleaved slices of 3 -mm thickness $(3 \times 3 \times 3.3 \mathrm{~mm}$ voxel size) aligned to the AC-PC plane. Overall, 171 volumes were acquired for each motor block, 305 for the syntactic task and 140 for the working memory task. T1-weighted images were acquired with a 1-mm isotropic voxel and a GeneRalized Autocalibrating Partial Parallel Acquisition (GRAPPA) acceleration factor of $2(\mathrm{TE}=3.8 \mathrm{~ms}, \mathrm{TR}=3000 \mathrm{~ms})$.

\section{Behavioral acquisition: Experiments 2 to 5}


In Experiment 2, following a short familiarization with five trials, participants performed the syntactic test before and after their respective training. A first group $(\mathrm{N}=26)$ trained with the tool. As controls, two additional groups either trained with the free hand $(\mathrm{N}=26)$ or simply watched videos $(\mathrm{N}=26)$. The linguistic material selected in the pre-test was always different from that presented in the post-test.

In Experiment 3, three groups of 13 participants were included, and each underwent one of three different motor training: tool-use, free-hand or constrained-hand training.

In Experiment 4, 48 participants were included and equally divided into two different groups ( $\mathrm{N}=24$ each) with a single-blind procedure by experimenter A. Each group underwent one of two different syntactic training: with object relative clauses or subject relative clauses. Regardless of the group, before and after the syntactic training, participants performed the motor test with the tool. To avoid potential observational bias, experimenter B supervised the motor test acquisition, whereas experimenter A gave instructions for the syntactic training. Experimenter B was blind with respect to which syntactic training condition each participant had been assigned to.

In experiment 5, 40 participants were included and divided in two different groups ( $\mathrm{N}=20$ each) tested on their ability to insert pegs with the tool or with the constrained hand, before and after a syntactic training with object relatives.

\section{$\underline{\text { Analyses }}$}

Experiment 1: fMRI analyses

Preprocessing. fMRI data were analyzed with statistical parametric mapping (SPM12; Wellcome Trust Centre for Neuroimaging). Functional data were preprocessed with a standard procedure. This consisted of spatial realignment, slice timing and coregistration of anatomical to mean functional images. Data were then spatially normalized into the MNI (Montreal Neurological Institute) stereotactic space with a resampling to $3 \times 3 \times 3 \mathrm{~mm}$. As last step, data were spatially smoothed using a 3D Gaussian kernel with full-width at half-maximum (FWHM) of $8 \mathrm{~mm}$ and temporally highpass filtered with a cutoff at $1 / 128 \mathrm{~Hz}$.

Univariate analyses. At the first level, each participant's hemodynamic responses were modeled with a box-car function. Each motor block was designed with planning, execution, rest and, as regressors of no interest, missed trials and head movements. Both directions of the movements (back and forth) were taken into consideration. For the syntactic task, we modeled the coordinated, 
subject relative and object relative clauses during sentence presentation (i.e., syntactic encoding) and test affirmation separately. This last part contains participants' RTs, incorrect responses and head movements, which were entered as regressors of no interest in the model. For the working memory task, hits, false alarms, correct rejections and miss trials as well as head movements were considered. At the second level, we conducted within-subjects ANOVAs to identify the general network underlying each assessed function. We computed the interaction contrast highlighting the specific tool-use planning neural network with respect to free-hand planning and the overall execution network:

Tool-use Planning Network $=[($ Tool-use Planning - Free-Hand Planning $)-($ Tool-use Execution - FreeHand Execution)].

To assess the specific syntactic neural network, we contrasted the activity in the encoding phase for object relative clauses with that in the encoding phase for both coordinated and subject relative clauses, for corrects trials only:

Syntax Network $=[2$ Object relative clauses $-($ Coordinated clauses + Subject relative clauses $)]$.

For working memory, we computed the difference between hits in the 3-back and 1-back tasks:

$$
\text { Working Memory Network }=\text { Hits 3-back }- \text { Hits 1-back. }
$$

These contrasts were then entered into conjunction analyses (minimum statistic compared to conjunction null hypothesis, (71)), allowing to assess the anatomical overlap between the different processes: Tool-use Planning Network $\frown$ Syntax Network, and as control, Tool-use Planning Network $\frown$ Working Memory Network.

As further control for the specificity of the shared functional activation between tool-use planning and syntax, we computed the hand planning network as follows:

Free-Hand Planning Network $=[($ Free-Hand Planning - Tool-use Planning $)-($ Free-Hand Execution Tool-use Execution)], 
and the conjunction Free-Hand Planning Network $\frown$ Syntax Network was assessed.

To investigate the network activated during action execution, we computed both the following:

Tool-use Execution Network = [(Tool-use Execution - Free-Hand Execution $)-($ Tool-use Planning Free-Hand Planning)]

and

Free-Hand Execution Network $=[($ Free-Hand Execution - Tool-use Execution $)-($ Free-Hand Planning Tool-use Planning)]

as well as further studied the conjunctions Tool-use Execution Network $\frown$ Syntax Network and Free-Hand Execution Network $\frown$ Syntax Network.

To guarantee the reliability of the results, for each analysis, we reported each cluster at the whole brain level, containing more than 10 contiguous voxels $\left(>270 \mathrm{~mm}^{3}\right)$, with a $p$-value below the 0.001 threshold uncorrected for multiple comparisons. Furthermore, each motor contrasts was submitted to an exclusive mask defined at 0.05 uncorrected for multiple comparisons aiming to rule out the contribution of the interaction second component (i.e., for Tool-use Planning Network, the contribution Hand Execution > Tool Execution was masked). This mask was also used for the conjunction analyses. Clusters passing the family-wise error (FWE) correction for multiple comparisons at the cluster level were highlighted.

Multivariate analyses. We then assessed our prediction of shared cognitive processes within the overlapping territories between tool-use planning and syntax. To this aim, we tested whether the brain activity level during tool-use planning, compared to free-hand planning, presented stronger pattern similarity with brain activity levels associated with object relative clauses.

For the first series of analyses, we used the CoSMoMVPA toolbox (72) to extract, for each participant, the nonsmoothed parameter estimates (beta) from each voxel of the overlapping clusters for both tool-use and free-hand planning. We did the same for object and subject relative clauses. This produced for each participant four vectors of parameter estimates (i.e., one per condition), composed of all significant voxels $(n=41)$ evidenced by the conjunction analysis. We then performed 
a representational similarity analysis (RSA). To this aim, for each participant, the four individual vectors were entered in a $4 \times 4$ similarity matrix, where each node represented the correlation (Pearson's $r$ ) between the activity patterns of two conditions. Higher correlation scores indicated better similarity. The obtained matrix was symmetrical with respect to the diagonal, containing six nodes of interest, corresponding to all pairwise comparisons between non-identical conditions. The similarity matrix obtained for each individual was then compared to hypothesis-driven models aiming to predict the data. A correlation between the observed similarity matrix and the model was computed as a measure of fit of the model: the higher the correlation coefficient, the better the fit of the model. Each individual correlation score was Fisher's z-transformed before any statistical analysis and tested with a unilateral sample t-test against zero with a Bonferroni correction applied to correct $p$-values for multiple comparisons.

We tested two models. Both models included within-domain similarity: between the two motor conditions and between the two most complex syntactic conditions. Crucially, the two models differed regarding the tested cross-domain similarity. The first model, represented by matrix 1 , tested the cross-domain similarity between tool-use planning and object relative clauses, whereas the second control model, represented by matrix 2, tested the cross-domain similarity between free-hand planning and object relative clauses. 
Matrix of similarity 1:

\begin{tabular}{|c|c|c|c|c|c|c|c|c|}
\hline & $T p$ & $F p$ & $S R C$ & $O R C$ & & & & \\
\hline$T p$ & 1 & 1 & 0 & 1 & & & & \\
\hline$F p$ & 1 & 1 & 0 & \multicolumn{5}{|c|}{ Matrix of similarity 2 : } \\
\hline $\begin{array}{l}S R C \\
O R C\end{array}$ & 0 & $\begin{array}{l}0 \\
0\end{array}$ & $\begin{array}{l}1 \\
1\end{array}$ & 1 & $T p$ & $F p$ & $S R C$ & $O R C$ \\
\hline & & & & ${ }^{1} T p$ & 1 & 1 & 0 & 0 \\
\hline & & & & $F p$ & 1 & 1 & 0 & 1 \\
\hline & & & & $S R C$ & 0 & 0 & 1 & 1 \\
\hline & & & & $O R C$ & 0 & 1 & 1 & 1 \\
\hline
\end{tabular}

$T p$ and $F p$ stand for tool-use planning and free-hand planning, respectively, whereas $S R C$ and $O R C$ indicate subject relative clauses and object relative clauses, respectively. Additionally, each node was defined by 1 or 0 , with 1 representing the similarity between a pair of vectors and 0 representing a dissimilarity.

To assess the specificity of the similarity between syntax and tool-use patterns, the same analysis was also run on working memory patterns as a control. In other words, we tested for possible crossdomain similarities between 3-back and tool-use patterns. To do so, we entered in the matrices of the models described above activity patterns elicited during 1-back and 3-back tasks, instead of object and subject relative patterns respectively.

We further tested whether the similarity between patterns can be exploited to accurately predict the activity elicited by complex syntactic structures from that elicited by tool-use. A classification based MultiVoxel Pattern Analysis (MVPA), employing a leave-one-subject-out procedure was run with the CoSMoMVPA toolbox. Data from the 41 significant voxels in the basal ganglia identified in the conjunction analysis was used as features for the classification. More specifically, a SVM classifier was trained on the nonsmoothed t-maps derived from motor activations (tool-use planning vs. baseline and free-hand planning vs. baseline) and then tested cross-domain on the activation elicited by object relatives against baseline. We normalized each feature employing the toolbox built-in function. At each iteration, the classifier trained on motor data from all subjects but one, iteratively left out. The classifier was then tested cross-domain on the object relatives data of all subjects ( $\mathrm{N}=20$ tests per iteration). This resulted in an average accuracy score for each iteration. The overall average score across all iterations was tested for significance after performing 10,000 permutations of neural patterns across subjects in order to estimate a null distribution. The p-values were calculated to test whether the observed difference was significantly and positively 
different from chance level (accuracy $=0.5$ ). The same procedure was subsequently used with the 3-back task to control for syntactic specificity, namely the SVM classifier was trained on the motor data and tested on the 3-back data.

Cluster-based voxelwise correlations. We studied in more detail the similarity between patterns of activity underlying tool-use planning and object relative clauses in each cluster, by computing voxelwise correlations (42). As a control, we calculated the same voxelwise correlations also between patterns of activity underlying free-hand planning and object relative clauses, in each cluster separately. To this aim, averaged contrast estimates (betas) were computed from the nonsmoothed images for each voxel for both tool-use planning and object relatives. This produced two vectors of betas per cluster, one for tool-use planning and one for object relatives. The correlation between the two vectors of the same cluster was assessed as a measure of the similarity of the spatial distribution of brain activity: a higher correlation coefficient indicates strong similarity. We repeated the same procedure to calculate the correlation between patterns of activity corresponding to freehand planning and object relatives. This procedure resulted in two Pearson's correlation scores: one for the relationship between tool-use planning and object relative clauses and a second for the relationship between free-hand planning and object-relative clauses. For comparison, the second score was subtracted from the first one, giving an observed difference in correlations. Statistical inference was allowed by comparing the observed difference to an empirical null distribution of differences obtained after 10,000 permutations across the features of the two motor conditions. The $p$-values were calculated to test whether the observed difference was significantly positive.

\section{Experiments 1 to 5: Behavioral data preprocessing}

For the syntax and verbal working memory tasks, response times (RTs; i.e., time interval from the display of the test affirmation or target word, respectively, to participant's response) and sensitivity index $\left(d^{\prime}\right)$ were measured to index performance. In the working memory task, to complement our analyses we also studied the proportion of hits and false alarms. Trials with RTs deviating from the mean \pm 2.5 standard deviations were removed from analysis. This represented in total $1.4 \%$ of the trials across all experiments. Statistics on these data were run in R-studio with built-in statistical functions and the afex package (73). The statistical models performed for each experiment are presented below. For all analyses, Tukey post hoc comparisons were performed to further explore significant interactions. All results are reported as the mean \pm SEM. 


\section{Experiments 1: Behavior Statistics}

For the syntactic task, we performed repeated measures ANOVAs (rmANOVA) on $d^{\prime}$ and linear mixed models (LMM) on RTs. The one-way ANOVA was performed with the within-subjects factor Sentence (Coordinated vs. Subject relative vs. Object relative clauses). The LMM performed on RTs included the same within-subject factor, with Subjects and Sentence as random factors. To account for differences in performance between the 1-back and 3-back working memory tasks, paired-sample t-tests were performed on $d^{\prime}$, proportion of hits and proportion of false alarms. RTs were assessed through LMM analysis with Difficulty (1-back vs. 3-back) as within-subject factor, with Subjects and Difficulty added as random factors.

\section{Experiments 2 and 3: Statistics}

To assess the progress in performance during motor training in each behavioral experiment, rmANOVAs on the number of inserted pegs were conducted with Block (9 blocks) as the withinsubjects factor and Training (Tool use vs. Free hand in Experiment 2 and Tool use vs. Free hand vs. Constrained hand in Experiment 3) as the between-subjects factor. To identify performance differences between training conditions, the total number of pegs inserted across the 9 blocks were assessed: in Experiment 2 by a two-sample t-test (Training: tool use vs. free hand) and in Experiment 3 with a one-way rmANOVA (Training: tool use vs. free hand vs. constrained hand).

We accounted for possible effects of participants' initial syntactic skills on the improvement in the post-test. This was done by conducting an ANCOVA on the RTs, entering the initial syntactic performance measured by the $d^{\prime}$ as a covariate, Sentence and Time as within-subjects factors, and Training as a between-subjects factor. Next, syntactic performance was analyzed through a LMM on RTs with Training (Tool use vs. Free hand vs. Video in Experiment 2 and Tool use vs. Free hand vs. Constrained hand in Experiment 3) as the between-subjects factor and Sentence (Coordinated vs. Subject relative vs. Object relative clauses) and Time (Pre vs. Post) as within-subjects factors. Subjects, Sentence and Time were added to account for random effects. rmANOVA was run on $d^{\prime}$, with Training (Tool use vs. Free hand vs. Video in Experiment 2 and Tool use vs. Free hand vs. Constrained hand in Experiment 3 ) as the between-subjects factor and Sentence (Coordinated vs. Subject relative vs. Object relative clauses) and Time (Pre vs. Post) as within-subjects factors. 
To quantify the robustness of the syntactic benefits after tool-use training across Experiments 2 and 3, we finally computed the effect size of the pre-to-post-test improvement in the syntactic task $(39,43)$. This was done by calculating the difference between pre- and post-test performance divided by the pooled standard deviation in the pre-test (for the entire sample of participants). The effect size in the object relative clauses condition was then analyzed in an rmANOVA with Training (Tool use vs. Free hand) and Experiment (Experiment 2 vs. 3) as between-subjects factors.

\section{Experiments 4 and 5: Statistics}

In the Experiment 4, to assess the progress in performance during syntactic training, an rmANOVA on $d^{\prime}$ and a LMM on RTs were conducted. The rmANOVA was performed with Block (6 blocks) as the within-subjects factor and Training (Object relative clauses vs. Subject relative clauses) as the between-subjects factor. The LMM performed on RTs included the same within-subject factor, with Subjects and Block as random factors.

Next, motor performance with the tool was analyzed through a LMM on the total number of inserted pegs with Training (Object relatives vs. Subject relatives) as the between-subjects factor and Time (Pre vs. Post) and Block (4 blocks) as within-subjects factors. Subjects, Time and Block were added to account for random effects.

Finally, to corroborate our results, motor performance was analyzed through an rmANOVA on the individual improvement slope $(\beta)$ with Training (Object relatives vs. Subject relatives) as the between-subjects factors and Time (Pre vs. Post) as within-subjects factors. Improvement slope was obtained by performing a linear regression over the number of inserted pegs for each participant, before and after syntactic training separately. Slopes were also compared against zero with onesample t-tests for object relatives and subject relatives separately. No difference against zero predicted no improvement (i.e. flat slope), whereas a significant difference predicted a change in performance, as indexed by a positive (i.e. increased performance) or negative (i.e. decreased performance) slope. A Bonferroni correction was applied to correct $p$-values for multiple comparisons. In Experiment 5, similar models to Experiment 4 were applied. To assess the progress in performance during syntactic training, we conducted an rmANOVA on $d^{\prime}$ and a LMM on RTs. The rmANOVA was performed with Block (6 blocks) as the within-subjects factor and Motor Test (Tool vs. Constrained Hand) as the between-subjects factor. The LMM performed on RTs included the same within-subject factor, with Subjects and Block as random factors. To evaluate motor performance, an rmANOVA was performed on the number of pegs inserted in pre- and post-tests. For 
pre-test, we considered the number of pegs inserted in the last block, namely when the participants reached the required motor threshold ( 8 pegs). Conversely, for post-test, we calculated the mean across the four blocks performed. The rmANOVA was performed with Time (Pre vs. Post) as the within-subjects factor and Motor Test (Tool vs. Constrained Hand) as the between-subjects factor. An rmANOVA was also conducted by considering only the post-test performance across the four blocks performed. The rmANOVA included Block (4 Blocks) as the within-subjects factor and Motor Test (Tool vs. Constrained Hand) as the between-subjects factor. In order to corroborate the effects found in the Experiment 4, paired-sample t-tests were performed between the last pre-test block (i.e. when the threshold was reached) and each of the post-test blocks separately for the tool and constrained-hand conditions. Two-sample t-tests were additionally conducted to compare the number of pegs inserted between the two motor conditions for each post-test block. A Bonferroni correction was applied to account for multiple comparisons. As in Experiment 4, we analyzed the improvement slope $(\beta)$. This was obtained by performing a linear regression over the number of inserted pegs for each participant after syntactic training. Slopes were also compared against zero with one-sample t-tests for tool use and constrained hand separately. A Bonferroni correction was applied to correct $p$-values for multiple comparisons. 


\section{Supplementary Text}

\section{Experiment 1}

\section{Tool and hand motor task: neural activity}

To reveal the neural overlap between tool use and syntax, we mainly focused on the planning phase of the action when participants were not yet moving. This was done by comparing brain activity elicited during action planning with the tool to that elicited during preparation of the same action with the free hand. Moreover, to properly isolate motor planning activity (36), the interaction contrast controlled for activity elicited by the actual execution of the action. Regarding specific freehand planning neural activity, the interaction contrast [Free-Hand Planning - Tool-use Planning] - [FreeHand Execution - Tool-use Execution] revealed a cluster of activation within occipital regions [xyz (-3, $79,-1), \mathrm{k}=122, p<0.05$ corrected for multiple comparisons at the cluster level; xyz $(-21,-79,-$ $7), \mathrm{k}=16, p<0.001$; xyz $(21,-76,-7), \mathrm{k}=13, p<0.001]$. However, closer inspection of contrast estimates did not show any activity specific to hand planning. This was confirmed by a direct comparison between free-hand planning and tool-use planning activity, which did not reveal any significant cluster of brain activation.

We also assessed brain activity elicited during action execution with the Tool-use Execution Network contrast and the Free-Hand Execution Network contrast. Four clusters in the occipital cortex displayed significant activations resulting from the Tool-use Execution Network contrast [xyz ($9,79,2), \mathrm{k}=282, p<0.05$ corrected for multiple comparisons at the cluster level; xyz $(-12,-79$, $17), \mathrm{k}=16, p<0.001 ; \operatorname{xyz}(3,-79,26), \mathrm{k}=34$; xyz $(27,-76,-7), \mathrm{k}=17, p<0.001]$. In line with previous work $(35,74)$, we interpreted this cortical activity as reflecting tool category-specific activation, resulting from mere tool observation and the visual properties of tool vs. free-hand action. In contrast, executing the action with the free hand, compared with the tool, produced stronger activity in the bilateral post-central sulcus [xyz $(-42,34,41), \mathrm{k}=45, p<0.001$; xyz $(33$, $-25,38), \mathrm{k}=55, p<0.001$ ] and the right hippocampus [xyz $(36,-22,-10), \mathrm{k}=25, p<0.001]$. We propose that the former activation might reflect additional sensory feedback during free-hand grasping/lifting actions (75) with respect to tool actions. Importantly, irrespective of the effector, the clusters activated by action execution did not overlap with the syntax neural network.

\section{Multivariate analyses}

In the main text, we reported stronger similarity between object relatives and tool-use planning neural patterns, rather than free-hand planning neural patterns, on the 41 overlapping voxels within 
the basal ganglia. For the RSA, the model assessing for representational similarity between tooluse planning and 3-back was not significant (Pearson's $r$ mean $=0.16 \pm 0.11$; Fisher's $z$ mean $=$ $0.20 \pm 0.15 ; \mathrm{t}_{(19)}=1.36 ; p=0.18$, Bonferroni-corrected). Similarly, testing for a similarity between free-hand planning and 3-back did not yield a good fit for the data (Pearson's $r$ mean $=-0.04 \pm$ 0.08 ; Fisher's $z$ mean $=-0.06 \pm 0.10 ; \mathrm{t}_{(19)}=-0.63 ; p=1.00$., Bonferroni-corrected). This was further corroborated by a SVM analysis using a leave-one-subject-out procedure, revealing that object relatives neural patterns were significantly classified above chance as tool use neural patterns rather than as free-hand planning. To control the specificity of these results, we performed these same two analyses using the working memory data instead of the syntactic data. This successful control converged with the results of the further control MVPA classification, where a classifier was trained on the motor patterns but tested on the 3-back ones. The classification accuracy did not significantly differ from chance level (accuracy $=0.67, p=0.15$ ). This result indicates that the successful classification is specific for the syntactic condition. In conclusion, we can rule out the contribution of verbal working memory as well as of free-hand planning to the neurocomputational resources shared by syntactic processing and tool use.

\section{Working memory: behavioral performance}

To compare the performance between the 3-back and 1-back tasks, we conducted a paired-sample t-test on $d^{\prime}$ and a LMM on RTs. As expected, this showed that the 3-back task was significantly more difficult $\left(d^{\prime}=2.13 \pm 0.24\right.$ and RTs $\left.=959 \pm 32 \mathrm{~ms}\right)$ than the 1 -back task $\left(d^{\prime}=4.46 \pm 0.08 ; \mathrm{t}_{(19)}\right.$ $=12.48 ; p<0.001 ;$ Cohen's $\mathrm{d}=2.94$ and RTs $\left.=821 \pm 27 \mathrm{~ms} ; \chi^{2}(1)=15.30, p<0.001\right)$. The proportion of hits was $70.7 \pm 4.9 \%$ for 3 -back and $97.4 \pm 0.7 \%$ for 1 -back $\left(\mathrm{t}_{(19)}=5.9 ; p<0.001\right.$, Cohen's $\mathrm{d}=1.71$ ) and the proportion of false alarms was $9.1 \pm 1.5 \%$ for 3 -back and $0.4 \pm 0.1 \%$ for 1-back $\left(\mathrm{t}_{(19)}=6.16 ; p<0.001\right.$, Cohen's $\left.\mathrm{d}=1.87\right)$.

\section{Working memory: neural activity}

The working memory neural network was assessed with the contrast Hits 3-back - Hits 1-back. This showed activations within the left middle frontal gyrus, the right superior frontal gyrus, the left caudate nucleus and bilateral activations within the inferior parietal lobules (see Table S2 for all details). This attentional network is consistent with that previously reported for working memory processes $(39,69)$. Importantly, nothing significantly survived to the conjunction with tool-use 


\section{Science}

Submitted Manuscript: Confidential

AIAAAS

activations. Therefore, working memory does not contribute to the common network for tool-use planning and syntax. 


\section{Experiment 2}

\section{Motor training}

We first tested the efficacy of both tool-use and free-hand training by quantifying individual motor improvement with the number of correctly inserted pegs in each training block (2-way Training $x$ Block rmANOVA: significant interaction $\left.\left[\mathrm{F}_{(5.2,261.5)}=5.35 ; p<0.001 ; \eta_{\mathrm{G}}{ }^{2}=0.016\right]\right)$. The participants improved from the first to the last block, both with the tool (Block $1=9 \pm 1$ pegs vs. Block $9=15 \pm 1$ pegs; $p<0.001$, Tukey post hoc) and the free hand (Block $1=47 \pm 1$ pegs vs. Block 9 $=58 \pm 2$ pegs; $p<0.001$, Tukey post hoc). Furthermore, as expected, the participants training with the tool inserted fewer pegs than those training with the hand, overall (tool use $=112 \pm 6$ pegs vs. free hand $=492 \pm 13$ pegs; $t_{(35.5)}=26.04 ; p<0.001$, Cohen's $d=7.22$ ), as well as in each of the nine blocks separately ( $p_{s}<0.001$, Tukey post hoc).

\section{Syntactic improvement: Main effects and interaction effects on RTs and $d^{\prime}$}

The LMM on RTs in the participants showing high initial syntactic skills revealed main effects of the factors Time $\left(\chi^{2}(1)=30.81, p<0.001\right)$ and Sentence $\left[\chi^{2}{ }_{(2)}=101.92, p<0.001\right]$. RTs were longer for object relative clauses than for subject relative clauses which in turn showed longer RTs compared to coordinated clauses. This overall reflects increasing difficulty for more complex syntactic structures.

As reported in the main text, the significant Training $\times$ Time $\times$ Sentence interaction revealed a selective improvement in correctly processing object relative clauses after tool-use training compared to free-hand training and video watching. Tukey post hoc tests also showed, irrespective of the training condition, a significant reduction in RTs in post-test compared to pre-test for coordinated clauses (tool use: pre-test RTs $=1397 \pm 104 \mathrm{~ms}$ vs. post-test RTs $=1233 \pm 114 \mathrm{~ms}$; freehand: pre-test RTs $=1564 \pm 83$ ms vs. post-test RTs $=1354 \pm 92 \mathrm{~ms}$; video: pre-test RTs $=1682$ $\pm 100 \mathrm{~ms}$ vs. post-test RTs $=1450 \pm 87 \mathrm{~ms} ; p_{\mathrm{s}}<0.05$ ), as well as for subject relative clauses (tool use: pre-test RTs $=1564 \pm 122 \mathrm{~ms}$ vs. post-test $\mathrm{RTs}=1310 \pm 126 \mathrm{~ms}$; free hand: pre-test $\mathrm{RTs}=$ $1717 \pm 91 \mathrm{~ms}$ vs. post-test RTs $=1473 \pm 88 \mathrm{~ms}$; video: pre-test RTs $=1831 \pm 105 \mathrm{~ms}$ vs. post-test RTs $\left.=1584 \pm 113 \mathrm{~ms} ; p_{\mathrm{s}}<0.001\right)$. This might reflect unspecific test-retest effects since RT reductions were also observed after watching videos. A significant Time $\times$ Sentence interaction was also found $\left[\chi^{2}(2)=6.53, p=0.03\right]$. All post hoc results were significant, with a tendency for object relatives to improve less than the two other sentence structures and for a reduction in the difference 
between subject relatives and coordinated clauses in post-test. No other main effects nor interactions were significant $\left[\chi_{\mathrm{s}}^{2}<4.07, p_{\mathrm{s}}>0.13\right]$. The 3-way rmANOVA on $d^{\prime}$ only showed main effects of Time $\left[\mathrm{F}_{(1,55)}=10.22 ; p=0.002 ; \eta_{G}^{2}=0.023\right]$ and Sentence $\left[\mathrm{F}_{(1.4,74.4)}=69.56 ; p<0.001 ; \eta_{G}{ }^{2}=\right.$ 0.268]. In agreement with the results on RTs, sensitivity increased in post-test relative to pre-test and was lower for object relative clauses than for coordinated and subject relative clauses. No other main effects nor interactions were found to be significant $\left[\mathrm{F}_{\mathrm{s}}<2.59 ; p_{\mathrm{s}}>0.06\right]$.

Syntactic improvement: Main effects and interaction effects on RTs and $d^{\prime}$ for participants with low initial syntactic skills

The LMM on RTs in the participants showing low initial syntactic skills revealed main effects of the factors Time $\left[\chi_{(1)}^{2}=13.65, p<0.001\right]$ and Sentence $\left[\chi_{(2)}^{2}=43.95, p<0.001\right]$. RTs were shorter in post-test than in pre-test and longer for object relative clauses than for subject relative clauses which in turn showed longer RTs compared to coordinated clauses. This reflected the increasing difficulty for more complex syntactic structures. No other main effects nor interactions were significant $\left[\chi^{2}<7.92, p_{\mathrm{s}}>0.09\right]$. The 3-way rmANOVA on $d^{\prime}$ showed main effects of Time $\left[\mathrm{F}_{(1,17)}=\right.$ 42.3; $\left.p<0.001 ; \eta_{G}^{2}=0.282\right]$ and Sentence $\left[\mathrm{F}_{(1.8,30.8)}=80.41 ; p<0.001 ; \eta_{G}{ }^{2}=0.59\right]$. In line with the results on RTs, sensitivity increased in post-test relative to pre-test and was lower for object relative clauses than for coordinated and subject relative clauses. No other main effects nor interactions were found to be significant $\left[\mathrm{F}_{\mathrm{s}}<2.24 ; p_{\mathrm{s}}>0.13\right]$.

Syntactic improvement: Main effects and interaction effects on RTs and d'for the whole sample of participants

The LMM on global RTs, independent of initial syntactic skills, confirmed the results described above. It revealed main effects of the factors Time $\left[\chi^{2}(1)=43.49, p<0.001\right]$ and Sentence $\left[\chi^{2}(2)=\right.$ 136.13, $p<0.001]$. Shorter RTs were found in the post-test than in the pre-test. RTs were also longer for object relative clauses than for coordinated and subject relative clauses, the latter showing longer RTs compared to coordinated clauses. The interaction between the two factors was also significant $\left[\chi_{(2)}^{2}=6.53, p=0.03\right]$. All post hoc results were significant, with a tendency for object relatives to improve less than the two other sentence types. No other main effects nor interactions were significant $\left[\chi^{2}<4.53, p_{\mathrm{s}}>0.23\right]$. The 3-way rmANOVA on $d^{\prime}$ only showed main effects of Time $\left[\mathrm{F}_{(1,75)}=31.56 ; p<0.001 ; \eta G^{2}=0.05\right]$ and Sentence $\left[\mathrm{F}_{(1.4,101.5)}=104.62 ; p<0.001 ; \eta G^{2}=\right.$ 0.27]. In agreement with the results on RTs, sensitivity increased in the post-test relative to the 
pre-test and was lower for object relative clauses than for coordinated and subject relative clauses. No other main effects nor interactions were significant $\left[\mathrm{F}_{\mathrm{s}}<2.2 ; p_{\mathrm{s}}>0.12\right]$. 


\section{Experiment 3}

\section{Motor training}

The participants improved [Training $\times$ Block interaction: $\mathrm{F}_{(9.9,178.6)}=3.6 ; p<0.001 ; \eta_{\mathrm{G}}{ }^{2}=0.039$ ] during tool-use training (Block $1=7 \pm 1$ pegs vs. Block $9=14 \pm 1$ pegs; $p<0.001$, Tukey post hoc), constrained-hand training (Block $1=4 \pm 1$ pegs vs. Block $9=11 \pm 1$ pegs; $p<0.001$, Tukey post hoc), as well as during free-hand training (Block $1=43 \pm 3$ pegs vs. Block $9=58 \pm 2$ pegs; $p<0.001$, Tukey post hoc). We checked whether increased sensorimotor difficulty with the constrained hand yielded poorer motor performance than free-hand training and equivalent performance with tool-use training. A one-way rmANOVA performed on the total number of inserted pegs revealed an effect of Training $\left[\mathrm{F}_{(2,36)}=324.9 p<0.001 ; \eta_{\mathrm{G}}{ }^{2}=0.948\right]$. As expected, Tukey post hoc showed that the participants training with the constrained hand inserted significantly fewer pegs $(84 \pm 5)$ than the participants training with the free hand $(486 \pm 20$ pegs; $p<0.001)$. Importantly, the number of pegs inserted by the constrained hand group did not differ from the number of pegs inserted by the tool-use group (106 \pm 6 pegs, $p=0.44)$. This held true even when considering each block separately [2-way Training $\times$ Block rmANOVA, significant interaction: $\left.\mathrm{F}_{(9.9,178.6)}=3.6 ; p<0.001 ; \eta_{\mathrm{G}}{ }^{2}=0.039\right]$. Participants inserted significantly fewer pegs with the constrained than the free hand $\left(p_{\mathrm{s}}<0.001\right)$. Crucially, the participants training with the constrained hand and those with the tool inserted a comparable number of pegs throughout the nine blocks $\left(p_{s}\right.$ $>0.33$ ). The motor performance thus validated the choice of the constrained hand to assess the potential contribution of sensorimotor difficulty to the cross-domain benefit.

\section{Syntactic improvement: Main effects and interaction effects on RTs and d'}

The LMM on RTs showed main effects of Time $\left[\chi^{2}(1)=38.7, p<0.001\right]$, Sentence $\left[\chi^{2}(2)=75.26, p\right.$ $<0.001]$ and Training $\left[\chi_{(2)}^{2}=9.4, p<0.009\right]$ whereas no interactions were found $\left[\chi^{2}<8.17 ; p_{\mathrm{s}}>\right.$ 0.08]. The Time and Sentence main effects reflected similar modulations as found in the previous Experiment 2. The main effect of Training was due to significantly slower RTs for the constrained hand group compared to the free hand group $(p=0.03)$.

The rmANOVA on $d^{\prime}$ also revealed main effects of Time $\left[\mathrm{F}_{(1,36)}=12.8 ; p=0.001 ; \eta_{G}^{2}=0.047\right]$ and Sentence $\left[\mathrm{F}_{(1.4,59.2)}=61.36 ; p<0.001 ; \eta_{G}^{2}=0.388\right]$. These effects accounted for identical modulations as reported in Experiment 2. The significant Training $\times$ Time $\times$ Sentence interaction discussed in the main text highlighted a selective improvement in processing object relative clauses after tool-use training compared to both free- and constrained-hand training. No such effect was 
found for coordinated clauses (tool-use pre-test $d^{\prime}=2.37 \pm 0.03$ vs. post-test $d^{\prime}=2.33 \pm 0.06$; freehand pre-test $d^{\prime}=2.25 \pm 0.06$ vs. post-test $d^{\prime}=2.29 \pm 0.06$; constrained-hand pre-test $d^{\prime}=2.27 \pm$ 0.05 vs. post-test $\left.d^{\prime}=2.32 \pm 0.08 ; p_{s}>0.67\right)$. Similarly for subject relative clauses, no significant improvement was observed after tool-use and free-hand training (tool-use pre-test $d^{\prime}=2.32 \pm 0.05$ vs. post-test $d^{\prime}=2.31 \pm 0.05$; free-hand pre-test $d^{\prime}=2.10 \pm 0.05$ vs. post-test $d^{\prime}=2.27 \pm 0.07 ; p_{s}>$ 0.11). Participants training with the constrained hand showed a significant improvement in this condition (pre-test $d^{\prime}=1.99 \pm 0.09$ vs. post-test $d^{\prime}=2.25 \pm 0.09 ; p=0.02$ ). However, the pre-test ability in processing subject relatives within the constrained hand group was significantly lower in comparison to the tool groups $(p=0.04)$, possibly explaining the differential progression from preto post-test. Additionally, a Time $\times$ Sentence interaction emerged $\left[\mathrm{F}_{(1.6,56.4)}=5.36 ; p=0.01 ; \eta_{G}{ }^{2}=\right.$ 0.027], explained by a significant improvement in post-test, irrespective of training, in processing object and subject relative compared to coordinated clauses. No other main effects nor interactions were found to be significant $\left[\mathrm{F}_{\mathrm{s}}<2.76 ; p_{\mathrm{s}}>0.07\right]$. 


\section{Experiment 4}

\section{Syntactic training}

We first tested the efficacy of both object relative and subject relative training by quantifying individual syntactic improvement with RTs and $d^{\prime}$ in each of the six training blocks. As expected, RTs in object relative group were longer $(1944 \pm 52 \mathrm{~ms})$ than those in the subject relative group $\left(1380 \pm 53\right.$ ms; two-way Training $\times$ Block rmANOVA: significant main effect of Training $\left[\chi^{2}(1)=\right.$ $16.00, p<0.001])$. Importantly, both groups improved similarly from the first to the last block of training (significant main effect of Block $\left[\chi^{2}(5)=84.64, p<0.001\right]$; no significant interaction of Block with Training $\left.\left[\chi^{2}(5)=4.16, p=0.52\right]\right)$.

The analysis on the $d^{\prime}$ confirmed these results (2-way Training $\times$ Block rmANOVA: main effect of Training $\left[\mathrm{F}_{(1,46)}=12.09 ; p=0.001 ; \eta_{G}^{2}=0.148\right]$ and of Block $\left[\mathrm{F}_{(3.9,180.1)}=25.69 ; p<0.001 ; \eta_{G}{ }^{2}\right.$ $=0.159])$. Participants in the object relative group showed lower $d^{\prime}(1.27 \pm 0.07)$ than participants in subject relative group $\left(d^{\prime}=1.79 \pm 0.04\right)$, reflecting more difficult processing of object relatives. Participants in both groups improved along the training. Moreover, the significant interaction between Block and Training $\left(\left[\mathrm{F}_{(3.9,180.1)}=3.35 ; p=0.01 ; \eta_{G}^{2}=0.024\right]\right)$ indicated a difference in performance $\left(d^{\prime}\right)$ over blocks between the groups (object relative group: Block $1=0.60 \pm 0.18$ vs. Block $6=1.64 \pm 0.16, p<0.001$; subject relative group: Block $1=1.47 \pm 0.12$ vs. Block $6=1.98$ $\pm 0.07, p<0.001)$. Tukey post hoc tests showed that the intergroup difference reduced along training, being significant from the $1^{\text {st }}$ to the $4^{\text {th }}$ blocks $\left(p_{\mathrm{s}}<0.03\right)$ and still remaining close to significant for the $5^{\text {th }}$ and $6^{\text {th }}$ blocks (non-significant $p_{\mathrm{s}}<0.09$ ). None of the two groups performed at ceiling at the end of training. This was confirmed by a one-sample t-test performed on the data for the $6^{\text {th }}$ block against the perfect performance $\left(d^{\prime}=2.17\right.$ reflected 8 hits and 8 correct rejections out of 16 trials), both for the group training with object relatives $\left[\mathrm{t}_{(23)}=3.43 ; p=0.004\right.$, Bonferroni-corrected Cohen's $\mathrm{d}=0.70]$ and the one training with subject relatives $\left[\mathrm{t}_{(23)}=2.68 ; p=0.02\right.$, Bonferronicorrected, Cohen's d $=0.55]$.

These results confirm the behavioral differences described in the three previous experiments in processing object relatives compared to subject relatives. Furthermore, both groups of participants similarly benefited from their respective training, improving their performance in processing syntactic structures.

\section{Tool-use improvement}


The LMM on the number of inserted pegs showed main effects of Time [Pre vs. Post; $\chi^{2}(1)=64.35$, $p<0.001]$ and Block [1 vs. 2 vs. 3 vs. $\left.4 ; \chi^{2}(3)=47.08, p<0.001\right]$. Participants significantly improved in using the tool after the syntactic training (inserted pegs in pre-test $=11.3 \pm 0.4$ vs. posttest $=14.0 \pm 0.4, p<0.001)$ and they significantly improved regardless of the pre- and post-test along the four block $\left(p_{s}<0.001\right)$.

\section{Experiment 5}

\section{Syntactic training}

As for the Experiment 4, we tested the efficacy of the object relative training by quantifying individual syntactic improvement with RTs and $d^{\prime}$ in each of the six training blocks for each of the two groups tested. Importantly, both groups improved similarly from the first to the last block of training (significant main effect of Block $\left[\chi^{2}(5)=41.69, p<0.001\right]$; no significant main effect of Motor Test nor interaction of Block with Motor Test $\left.\left[\chi^{2}<2.89, p>0.08\right]\right)$. The analysis on the $d^{\prime}$ confirmed these results (2-way Motor Test $\times$ Block rmANOVA: main effect of Block $\left[\mathrm{F}_{(4.2,158.5)}=\right.$ 21.11; $\left.p<0.001 ; \eta_{G}^{2}=0.171\right]$; no significant main effect of Motor Test nor interaction of Block with Motor Test $\left.\left[\mathrm{F}_{\mathrm{s}}<0.15 ; p>0.64\right]\right)$. Both groups of participants similarly benefited from their respective linguistic training, improving their performance in processing syntactic structures.

\section{Motor improvement}

The rmANOVA on the number of pegs inserted between pre- and post-test showed a main effect of Time [Pre vs. Post; $\mathrm{F}_{(1,38)}=36.48 ; p<0.001 ; \eta_{G^{2}}=0.163$ ] but not of Motor Test [Tool vs. Constrained Hand; $\left.\mathrm{F}_{(1,38)}=3.28 ; p=0.07\right]$. The Motor Test $\times$ Time interaction was significant $\left[\mathrm{F}_{(1,38)}=5.06 ; p=0.03 ; \eta_{G}^{2}=0.026\right]$. The post-hoc tests revealed a significant increase of the number of pegs inserted by both groups after compared to before linguistic training (inserted pegs with the tool pre-test $=11.0 \pm 0.6$ vs. tool post-test $=13.3 \pm 0.6, p<0.001$; inserted pegs with the constrained hand pre-test $=10.1 \pm 0.4$ vs. constrained-hand post-test $=11.3 \pm 0.5 ; p=0.01)$. However, despite the indistinguishable performance in pre-test (i.e. required motor threshold, see Methods, $p=0.54)$, the tool-use group significantly outperformed the constrained-hand group $(p=0.01)$ after syntactic training with object relatives.

We analyzed in more detail the post-test motor performance after syntactic training. The rmANOVA on the number of pegs inserted in post-test across the four blocks revealed a main effect of Block $\left[\mathrm{F}_{(2.7,103.5)}=6.32 ; p<0.001\right]$, reflecting the performance increase from the first to 
the fourth block. A main effect of Motor Test was also found $\left[\mathrm{F}_{(1,38)}=6.61 ; p=0.01\right]$, due to the greater number of pegs inserted by the tool than by the constrained-hand group across the four post-test blocks (tool $=13.3 \pm 0.6$ vs. constrained hand $=11.3 \pm 0.5$ ). No Motor Test $\times$ Block interaction was found $\left[\mathrm{F}_{(2.7,103.5)}=1.87 ; p=0.14\right]$. Planned comparisons on the number of pegs inserted between the pre and each of the post-test blocks revealed a significant difference for the last three post-test blocks for tool use ( $p_{s}<0.01$, Bonferroni corrected), but only for the last postblock for the constrained hand group ( $p=0.02$, Bonferroni corrected). Furthermore, comparisons of the performance in each post-test block between the motor conditions revealed that the tool-use group inserted significantly more pegs than the constrained-hand group in the third post-test block ( $p=0.01$, Bonferroni corrected), as in Experiment 4.

Finally, these results were corroborated by the analysis of the improvement slope in post-test. For the tool-use performance the positive slope $(\beta=0.93 \pm 0.25)$ differed significantly from zero [ $\mathrm{t}_{(19)}$ $=3.75 ; p=0.002$, Bonferroni-corrected, Cohen's $d=0.84$ ], indicating that participants kept on improving in using the tool after object-relative syntactic training. By contrast, for the constrainedhand group the slope of the motor performance did not differ significantly from zero $[\beta=0.48 \pm$ $0.29, \mathrm{t}_{(19)}=1.64 ; p=0.23$, Bonferroni-corrected], indicating null improvement.

These findings fully corroborate those of Experiment 4 of a transfer between linguistic training with object relatives and tool use. Furthermore, they emphasize the specificity of the transfer effect between the two domains, since a motor task featuring similar sensorimotor constraints as tool use did not equally benefit from the linguistic training. 


\section{Quantification of effect size across Experiments 2 and 3}

We further quantified the robustness of the cross-domain transfer from tool use to syntax by analyzing the effect size of the syntactic improvement $(39,43)$ following different training (tool use vs. free hand) across the two experiments (Experiments 2 vs. 3). We found that the benefits in syntactic comprehension of object relative clauses after tool-use as compared to free-hand training are consistent and of equivalent magnitude across experiments [Fig. 3F; 2-way Training $\times$ Experiment rmANOVA: significant main effect of Training $\left(\mathrm{F}_{(1,60)}=5.37 ; p=0.02 ; \eta_{G}{ }^{2}=0.082\right)$, nonsignificant effect of Experiment $\left(\mathrm{F}_{(1,60)}=2.8 ; p=0.11\right)$ nor any interaction $\left(\mathrm{F}_{(1,60)}=0.51 ; p=\right.$ 0.58)].

\section{Initial syntactic skills for Experiments 2 and 3}

To ensure that the improvement in post-test did not pertain to different syntactic skills before training, we controlled for pre-test syntactic performance between the training groups of Experiments 2 and 3. In the description of these experiments in the main text, we reported significant Training $\times$ Time $\times$ Sentence interactions, and Tukey post hoc tests did not show any difference in pre-test performance between groups for object relatives $\left(p_{\mathrm{s}}>0.63\right)$ nor for coordinated $\left(p_{\mathrm{s}}>0.09\right)$. In experiment 3 a significant difference appeared for subject relative clauses between tool-use and constrained-hand groups ( $p=0.04)$, whereas all the remaining comparisons remain non-significant $\left(p_{\mathrm{s}}>0.18\right)$. To ensure that the groups were homogeneous, we conducted additional analyses on $d^{\prime}$ and RTs, only considering pre-test performance with the three syntactic structures.

For $d^{\prime}$, a 2-way rmANOVA including Training as between-subjects and Sentence as within-subjects factors was performed for Experiments 2 and 3 separately. This did not reveal any main effect of Training nor any interaction $\left[\mathrm{F}_{\mathrm{s}}<2.32 ; p_{\mathrm{s}}>0.11\right]$. RTs were modeled with a LMM including the same factors as well as Subjects and Sentence as random effects. This analysis revealed a main effect of Training $\left[\chi_{\mathrm{s}}^{2}>6.17 ; p_{\mathrm{s}}<0.04\right]$ for both Experiments 2 and 3, however post-hoc tests did not show difference between groups, with the smallest $p$-value $(p=0.09)$ found for a planned comparison between free-hand and constrained-hand groups in Experiment 3. Furthermore, the Training $\times$ Condition interaction $\left[\chi^{2}{ }_{\mathrm{s}}<3.54 ; p_{\mathrm{s}}>0.47\right]$ was not significant. In summary, these analyses showed that the specific improvement in object relatives after tool-use training cannot be attributed to differences in pre-test performance. 


\section{Sociodemographic information}

To rule out any effect of participant sociodemographic information (age, education level and handedness) on training, we compared this information between training groups in Experiments 2 and 3 via a series of one-way ANOVAs.

In Experiment 2, the three groups of participants with high initial syntactic skills were comparable in terms of age (tool use: $23 \pm 3$ years old, free hand: $23 \pm 3$ years old and video: $22 \pm 2$ years old, $\mathrm{F}_{(2,55)}=1.89 ; p=0.16$ ), education level (tool use: $4 \pm 2$ years, free hand: $4 \pm 1$ years and video: 3 \pm 1 years, $\mathrm{F}_{(2,55)}=1.58 ; p=0.21$ ), and handedness (tool use: $0.85 \pm 0.13$, free hand: $0.91 \pm 0.11$ and video: $\left.0.92 \pm 0.11, \mathrm{~F}_{(2,55)}=1.80 ; p=0.17\right)$.

The same was observed in Experiment 3 for education level (tool use: $4 \pm 1$ years, free hand: $3 \pm$ 2 years and constrained hand: $4 \pm 2$ years, $\mathrm{F}_{(2,36)}=1.19 ; p=0.31$ ), and handedness (tool use: 0.88 \pm 0.12 , free hand: $0.87 \pm 0.14$ and constrained hand: $\left.0.88 \pm 0.12, \mathrm{~F}_{(2,36)}=0.39 ; p=0.68\right)$. A significant main effect of age $\left[\mathrm{F}_{(2,36)}=3.94 ; p=0.02 ; \eta_{G^{2}}=0.180\right]$ was found, indicating the average age of the constrained hand group ( $27 \pm 6$ years old) significantly differed from the free hand group (22 \pm 3 years, $p=0.02$ ). No difference was observed between the tool-use group $(24 \pm 5$ years $)$ and any of the two other groups $\left(p_{\mathrm{s}}>0.25\right)$.

In Experiment 4, we tested for potential differences in sociodemographic characteristics (age, education level and handedness) between the two training groups (object relatives vs. subject relatives) via a series of two-sample t-tests. The two groups of participants were comparable in terms of age (object relatives: $27 \pm 6$ years old and subject relatives: $27 \pm 5$ years old, $\mathrm{t}_{(46)}=0.06 ; p=$ 0.95); education level (object relatives: $4 \pm 2$ years and subject relatives: $5 \pm 3$ years, $\mathrm{t}_{(46)}=0.86$; $p=0.39$ ); and handedness (object relatives: $0.89 \pm 0.11$ and subject relatives: $0.88 \pm 0.10, \mathrm{t}_{(46)}=$ $0.28 ; p=0.78)$.

In the Experiment 5, the two groups were also equivalent in terms of age (tool: $27 \pm 8$ years old and constrained hand: $27 \pm 5$ years old, $\mathrm{t}_{(38)}=0.22 ; p=0.82$ ); education level (tool: $4 \pm 2$ years and constrained hand: $4 \pm 1$ years, $\mathrm{t}_{(38)}=1.36 ; p=0.18$ ) and handedness (tool: $0.94 \pm 0.09$ and constrained hand: $0.90 \pm 0.10, \mathrm{t}_{(38)}=1.14 ; p=0.26$ ). 
A

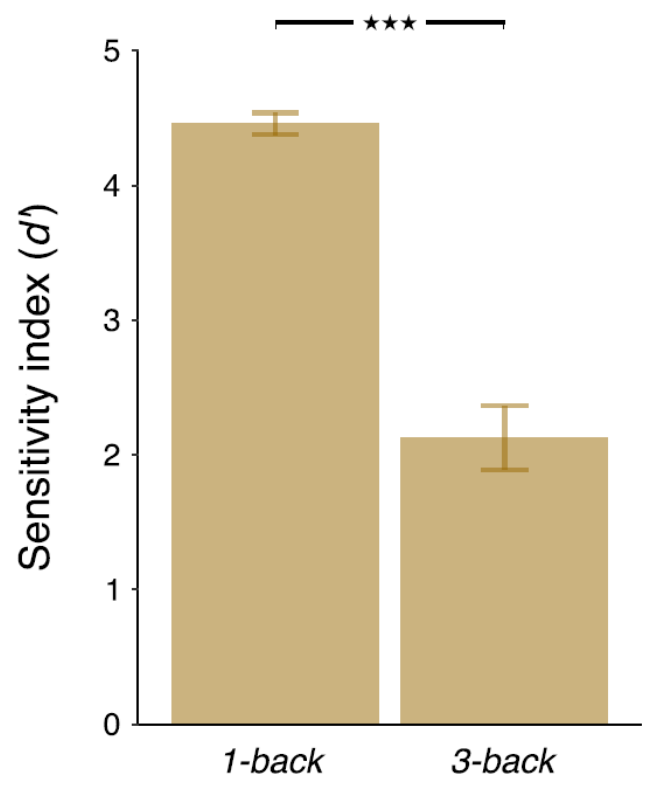

B

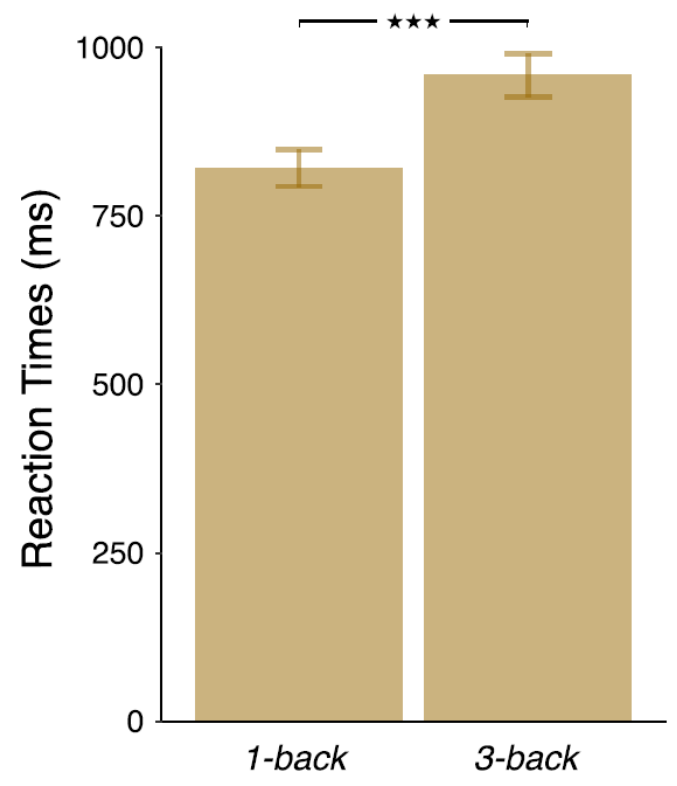

Fig. S1. Experiment 1: -back behavioral performance. (A) Mean sensitivity index ( $d^{\prime}$ ). (B) Mean Reaction Times (RTs) for the 1-back and 3-back tasks. Analyses revealed a memory load effect in the 3-back condition compared to the 1 -back condition, with reduced sensitivity index $\left(d^{\prime}\right)$ and longer RTs. ***p $<0.001 ; * * p<0.01 ; * p<0.05$. 


\section{WORKING MEMORY NETWORK}
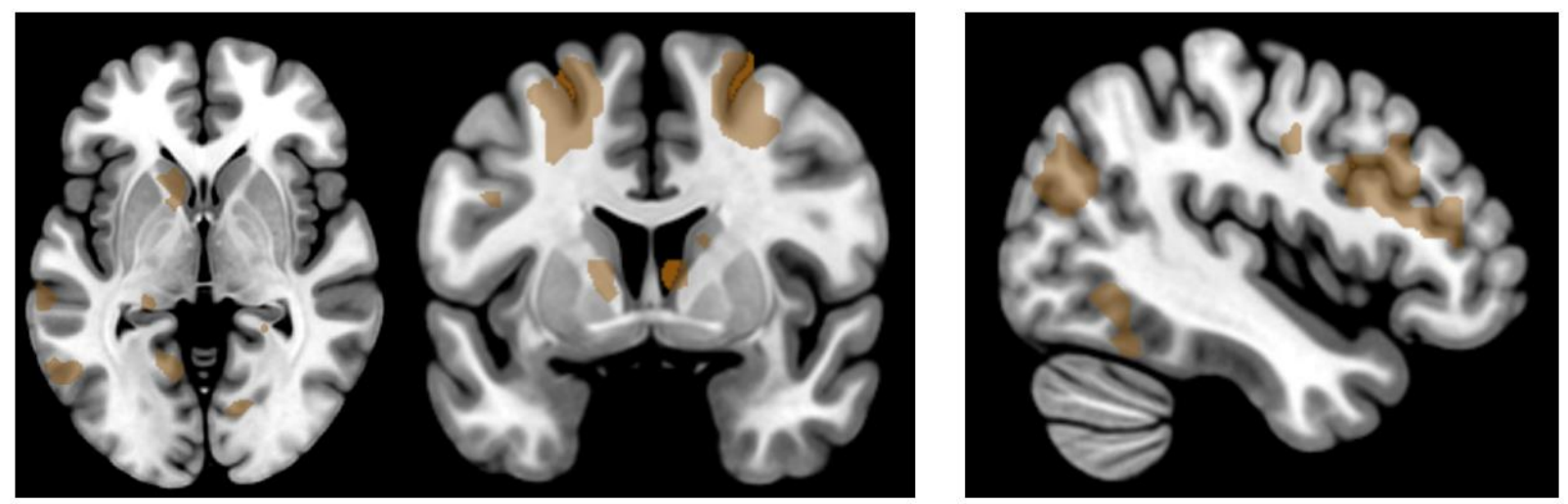

Fig. S2. Experiment 1: Statistical maps thresholded at $p<0.001$, unc., for verbal working memory (3-back vs. 1-back). 


\section{A LINGUISTIC IMPROVEMENT SUBJECT RELATIVES}

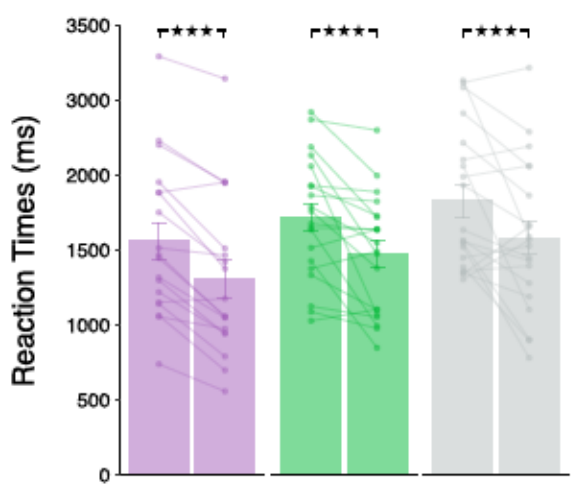

C

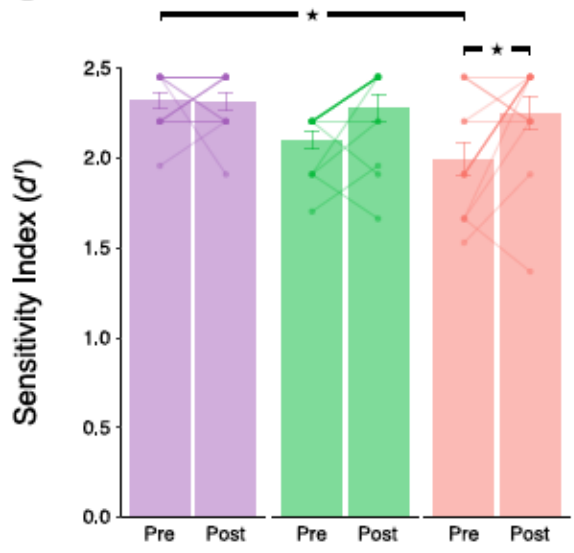

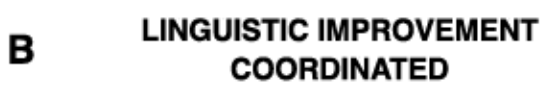

TRAINING

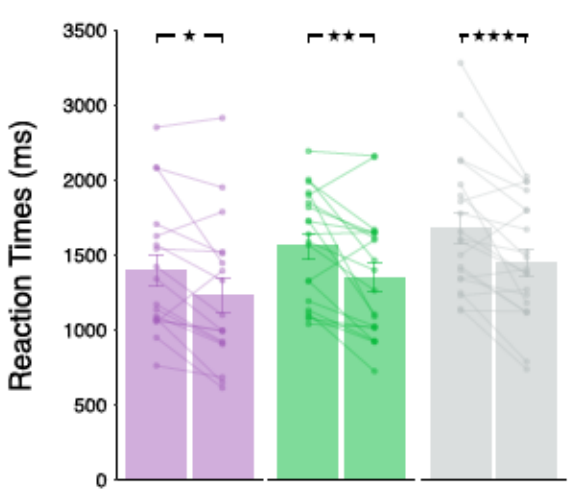

Tool use

Free hand

Constrained hand

Video

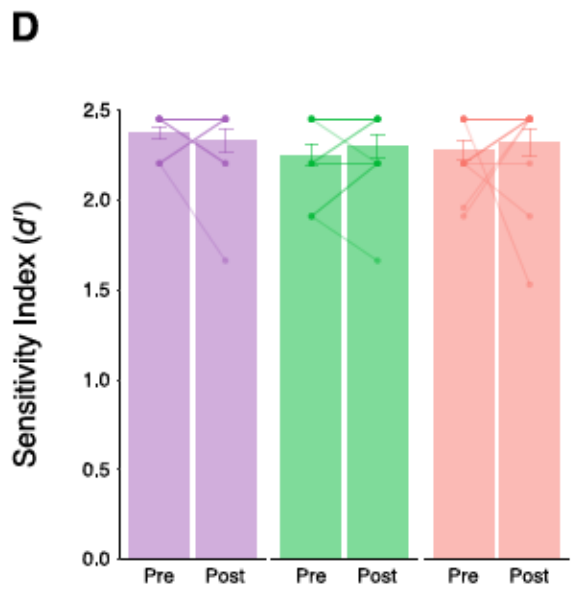

Fig. S3. Experiments 2 and 3: Lack of training group differences for subject relative and coordinated clause comprehension. In Experiment 2 (top panel), (A) for subject relative clauses and (B) coordinated clauses, no group difference was found on RTs. All training groups showed significantly shorter RTs in post-test with respect to pretest. In Experiment 3 (bottom panel) (C) for subject relative clauses and (D) coordinated clauses, no group difference was found on $d^{\prime}$. Performance did not significantly vary between the pre- and post-test. Each dot linking pre-test to a post-test dot represents an individual participant. ${ }^{* * *} p<0.001 ; * * p<0.01 ; * p<0.05$. 
A

PRE-TEST
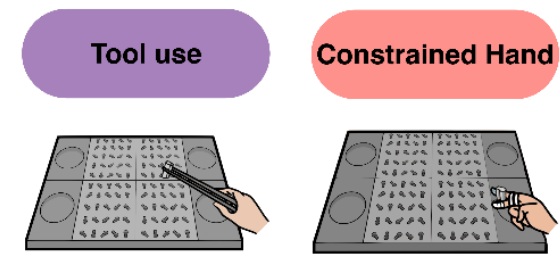

SYNTACTIC TRAINING

B

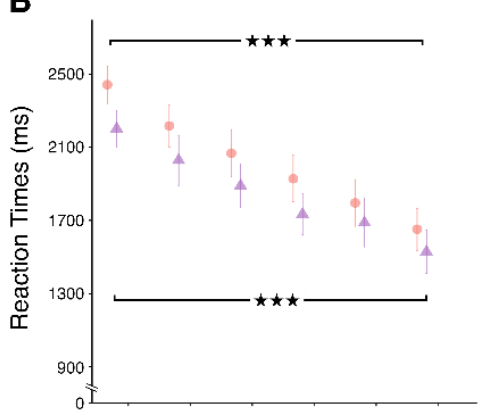

C

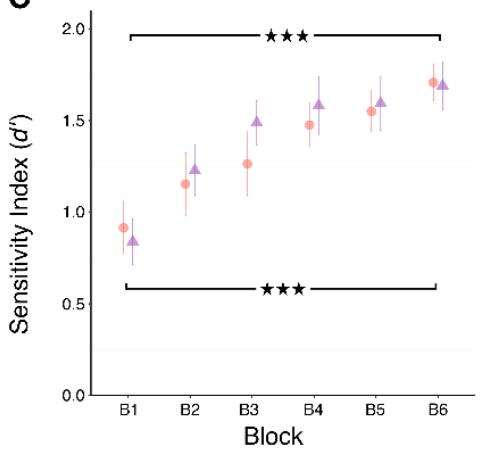

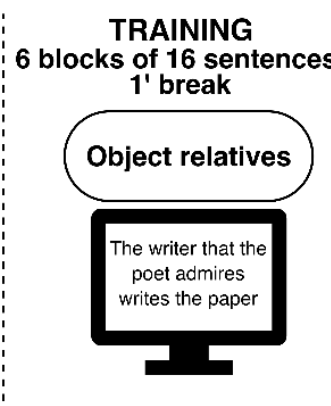

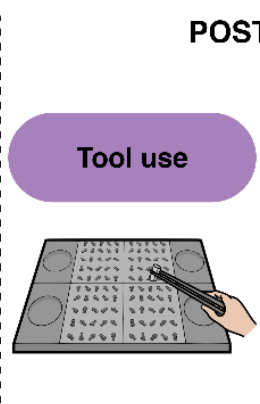

POST-TEST

MOTOR IMPROVEMENT

D

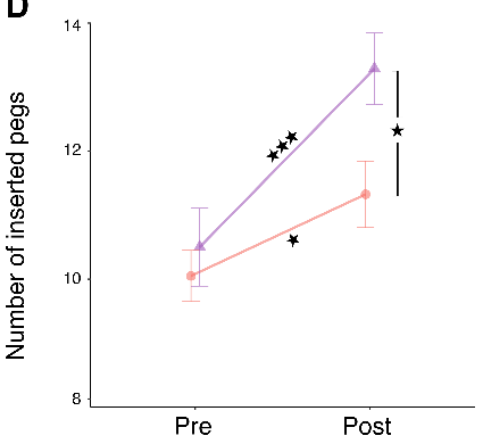

E

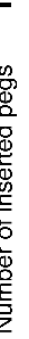

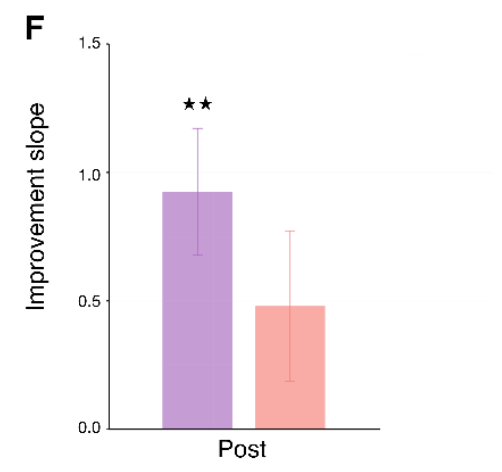

$F$
MOTOR TEST

Tool use

Constrained hand

Fig. S4. Experiment 5: Cross-domain learning transfer from syntax in language to tool use. (A) Timeline of syntactic training and motor pre- and post-tests. Two groups were tested in entering pegs as fast as possible with the tool (purple) or the constrained hand (red), before and after training with object relative clauses. (B-C) Linguistic progress in (B) RTs and (C) sensitivity ( $d^{\prime}$ ) during syntactic training. (D) Motor performance, assessed with the number of pegs inserted, significantly improved between pre- and post-test for both tool use and constrained hand. The tool-use group inserted significantly more pegs across the four post-test blocks than the constrained-hand group. (E) Number of pegs inserted in the last pre-test block, when the threshold was reached and for each of the four post-test blocks. Within-group planned comparisons revealed a significant difference between pre-test and post-test blocks, from the $2^{\text {nd }}$ to the $4^{\text {th }}$ ones, for tool use, therefore confirming the results of Experiment 4 . For the constrained hand the pre-test only differed compared to the $4^{\text {th }}$ (last) block post-test. (F) Motor improvement quantified with the slope of the regression line along the progression from the $1^{\text {st }}$ to the $4^{\text {th }}$ block of tool use and constrained hand after training with object relative structures in language. ${ }^{* * *} p<0.001 ; * * p<0.01 ;{ }^{*} p<0.05$. 


Region $\quad$ BA $\quad \begin{array}{ccc}\text { Peak MNI } & \text { Cluster } & \text { Z-value } \\ \text { coordinates } & \text { size }(k)\end{array}$

$x \quad y \quad z$

\section{(A) Syntax Network: 2 Object relative clauses - (Subject relative clauses + Coordinated} clauses)

$\begin{array}{lllllll}\begin{array}{l}\text { L Striatum (cluster extending to } \\ \text { Globus Pallidus) }\end{array} & - & -18 & 14 & -1 & 179 & 4.54 \\ & & & & & & \\ \text { L Inferior Frontal Gyrus }^{1} & \text { BA45 } & -42 & 29 & 5 & 28 & 4.05 \\ & & & & & & \\ \text { L Angular Gyrus } & \text { BA39 } & -42 & -52 & 32 & 14 & 3.69\end{array}$

R Striatum (cluster extending to Globus Pallidus) $)^{\mathrm{FWE}}$

$\begin{array}{lllll}15 & 11 & -1 & 177 & 4.32\end{array}$

R Angular Gyrus

BA39

51

$-49 \quad 26$

$30 \quad 3.94$


(B) Tool-use Planning Network: (Tool-use Planning - Free-Hand Planning) - (Tool-use Execution - Free-Hand Execution)

\begin{tabular}{|c|c|c|c|c|c|c|}
\hline $\begin{array}{l}\text { L Postcentral Gyrus (extending to } \\
\text { Supramarginal Gyrus) }\end{array}$ & $\begin{array}{l}\text { BA1, 2, } \\
3,40\end{array}$ & -63 & -19 & 29 & 147 & 4.25 \\
\hline $\begin{array}{l}\text { L Globus Pallidus (extending to } \\
\text { Caudate) }\end{array}$ & - & -6 & -4 & -10 & 124 & 4.83 \\
\hline L Inferior Frontal Gyrus² & BA44 & -60 & 11 & 26 & 37 & 3.99 \\
\hline L Occipitotemporal Cortex & BA19 & -51 & -73 & -10 & 31 & 3.69 \\
\hline L Supramarginal Gyrus & BA40 & -33 & -37 & 38 & 26 & 3.64 \\
\hline L Putamen & - & -33 & -13 & -7 & 14 & 3.62 \\
\hline \multirow[t]{2}{*}{$\begin{array}{l}\text { R Striatum (cluster extending to } \\
\text { Globus Pallidus) FWE }\end{array}$} & - & 33 & -16 & -7 & 750 & 5.34 \\
\hline & & 30 & -1 & 17 & 11 & 3.66 \\
\hline R Supramarginal Gyrus ${ }^{\mathrm{FWE}}$ & BA40 & 36 & -34 & 44 & 196 & 4.54 \\
\hline $\begin{array}{l}\text { R Postcentral Gyrus (extending to } \\
\text { Supramarginal Gyrus) }\end{array}$ & $\begin{array}{l}\text { BA1, } 2, \\
3,40\end{array}$ & 57 & -19 & 35 & 52 & 4.11 \\
\hline R Occipitotemporal Cortex & BA37 & 48 & -55 & -13 & 37 & 3.63 \\
\hline R Superior Temporal Gyrus & BA22 & 66 & -19 & -1 & 17 & 3.61 \\
\hline R Ventral Premotor Cortex & BA6 & 60 & 8 & 26 & 14 & 3.48 \\
\hline
\end{tabular}




\section{(C) Conjunction Syntax Network $\cap$ Tool-use Planning Network}

\begin{tabular}{lllllll}
\hline L Globus Pallidus & - & -12 & 5 & -4 & 14 & 3.48 \\
L Caudate Nucleus & - & -21 & 20 & 2 & 13 & 3.54 \\
R Globus Pallidus & - & 12 & -1 & 2 & 14 & 3.66
\end{tabular}

Table S1. Brain areas activated for syntax (A), tool-use planning (B) and their conjunction (C). All presented clusters contain more than 10 contiguous voxels and are below the statistics threshold $p<0.001$, unc. Clusters passing the family-wise error correction with $p<0.05$ at the cluster level are indicated with the mention ${ }^{\mathrm{FWE}}$. ${ }^{1}$ Pars triangularis; ${ }^{2}$ Pars opercularis. 


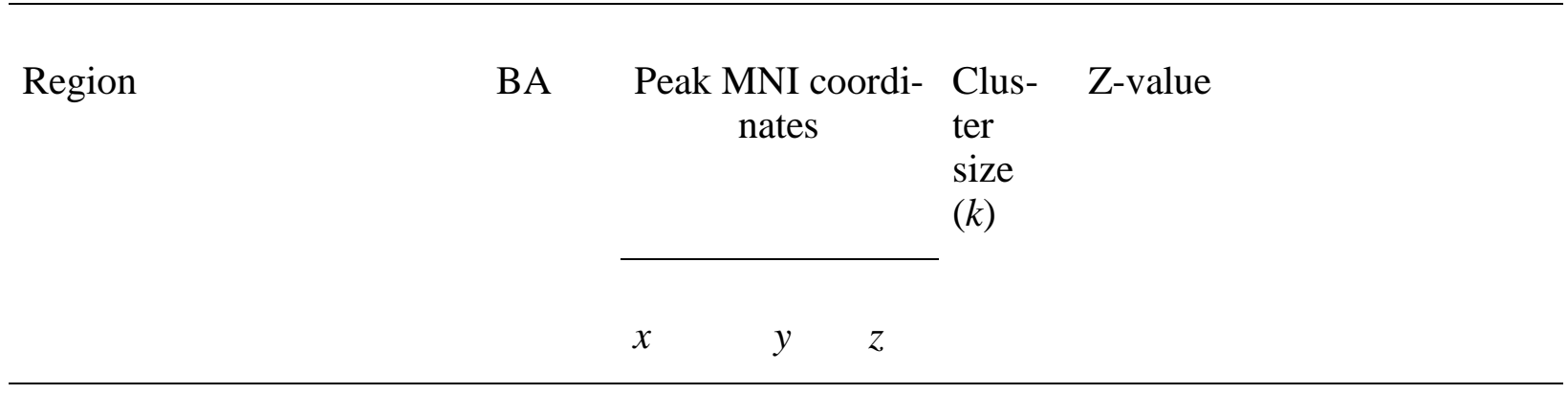

Working Memory Network $=$ Hits 3-back - Hits 1-back

\begin{tabular}{lllllll}
\hline L Angular Gyrus $^{\mathrm{FWE}}$ & BA39 & -30 & -67 & 32 & 1931 & 5.61
\end{tabular}

$\begin{array}{lllllll}\text { L Middle Frontal Gyrus }^{\text {FWE }} \quad \text { BA6 } & -24 & 14 & 47 & 673 & 5.78\end{array}$

$\begin{array}{lllllll}\text { L Dorsolateral Prefrontal } & \text { BA46 } & -48 & 35 & 17 & 314 & 4.40\end{array}$

Cortex $^{\text {FWE }}$

$\begin{array}{lllllll}\text { L Inferior Temporal Gy- } \quad \text { BA20 } & -48 & -58 & -10 & 156 & 4.11\end{array}$ rus FWE

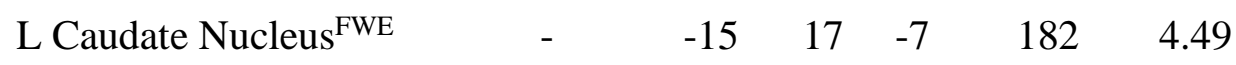

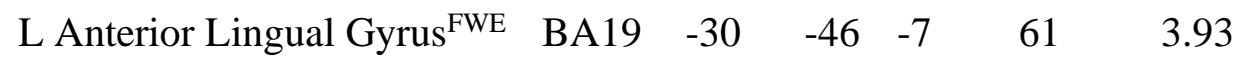

$\begin{array}{lllllll}\text { L Midbrain }^{\text {FWE }} \quad-\quad & -9 & -28 & -7 & 53 & 4.13\end{array}$

$\begin{array}{lllllll}\text { L Anterior Prefrontal Cortex } & \text { BA10 } & -18 & 59 & 14 & 42 & 4.87\end{array}$

$\begin{array}{lllllll}\text { L Precentral Gyrus } & \text { BA4 } & -51 & -7 & 35 & 40 & 4.29\end{array}$

$\begin{array}{lllllll}\text { L Middle Temporal Gyrus } & \text { BA21 } & -60 & -10 & -10 & 29 & 4.26\end{array}$

$\begin{array}{lllllll}\text { L Posterior Lingual Gyrus } \quad \text { BA18 } & -12 & -76 & -10 & 11 & 3.81\end{array}$ 


\begin{tabular}{|c|c|c|c|c|c|c|}
\hline R Superior Frontal Gyrus ${ }^{\mathrm{FWE}}$ & BA6 & 24 & -1 & 53 & 522 & 5.78 \\
\hline R Angular Gyrus ${ }^{\mathrm{FWE}}$ & BA39 & 39 & -76 & 29 & 326 & 4.77 \\
\hline $\begin{array}{l}\text { R Medial Orbitofrontal Cortex } \\
\text { (extending bilaterally) }\end{array}$ & BA11 & 9 & 32 & -13 & 177 & 4.00 \\
\hline R Posterior Lingual Gyrus ${ }^{\mathrm{FWE}}$ & BA18 & 15 & -76 & -7 & 98 & 3.92 \\
\hline R Caudate Nucleus & - & 18 & 17 & 5 & 47 & 4.47 \\
\hline R Anterior Lingual Gyrus & BA19 & 27 & -43 & -7 & 43 & 3.93 \\
\hline R Cerebellum Crus I & - & 36 & -70 & -31 & 41 & 4.02 \\
\hline R Cerebellum Lobule IX & - & 9 & -55 & -49 & 25 & 4.54 \\
\hline R Cerebellum Lobule VIIb & - & 30 & -70 & -46 & 22 & 3.92 \\
\hline R Precentral Gyrus & BA4 & 51 & -4 & 32 & 12 & 3.41 \\
\hline
\end{tabular}

Table S2. Brain areas activated for working memory. All presented clusters contain more than 10 contiguous voxels and are below the statistics threshold $p<0.001$, unc. Clusters passing the family-wise error correction with $p<0.05$ at the cluster level are indicated with the mention FWE. 


\begin{tabular}{|c|c|c|}
\hline Coordinated clauses & Subject relative clauses & Object relative clauses \\
\hline $\begin{array}{l}\text { L'adversaire contente le marin et re- } \\
\text { fait la partie }\end{array}$ & $\begin{array}{l}\text { L'adversaire qui contente le marin re- } \\
\text { fait la partie }\end{array}$ & $\begin{array}{l}\text { L'adversaire que le marin contente re- } \\
\text { fait la partie }\end{array}$ \\
\hline $\begin{array}{l}\text { L'amiral délivre l'alcoolique et pié- } \\
\text { tine le drapeau }\end{array}$ & $\begin{array}{l}\text { L'amiral qui délivre l'alcoolique pié- } \\
\text { tine le drapeau }\end{array}$ & $\begin{array}{l}\text { L'amiral que l'alcoolique délivre pié- } \\
\text { tine le drapeau }\end{array}$ \\
\hline $\begin{array}{l}\text { L'architecte nourrit la copine et pré- } \\
\text { pare le dîner }\end{array}$ & $\begin{array}{l}\text { L'architecte qui nourrit la copine pré- } \\
\text { pare le dîner }\end{array}$ & $\begin{array}{l}\text { L'architecte que la copine nourrit pré- } \\
\text { pare le dîner }\end{array}$ \\
\hline $\begin{array}{l}\text { L'artisan surprend le fermier et dé- } \\
\text { vore le dessert }\end{array}$ & $\begin{array}{l}\text { L'artisan qui surprend le fermier dé- } \\
\text { vore le dessert }\end{array}$ & $\begin{array}{l}\text { L'artisan que le fermier surprend dé- } \\
\text { vore le dessert }\end{array}$ \\
\hline $\begin{array}{l}\text { L'assistante appelle l'employé et net- } \\
\text { toie la cuisine }\end{array}$ & $\begin{array}{l}\text { L'assistante qui appelle l'employé } \\
\text { nettoie la cuisine }\end{array}$ & $\begin{array}{l}\text { L'assistante que l'employé appelle } \\
\text { nettoie la cuisine }\end{array}$ \\
\hline $\begin{array}{l}\text { L'écrivain admire le poète et écrit le } \\
\text { papier }\end{array}$ & $\begin{array}{l}\text { L'écrivain qui admire le poète écrit le } \\
\text { papier }\end{array}$ & $\begin{array}{l}\text { L'écrivain que le poète admire écrit le } \\
\text { papier }\end{array}$ \\
\hline $\begin{array}{l}\text { L'espagnol envie la danseuse et } \\
\text { adore le spectacle }\end{array}$ & $\begin{array}{l}\text { L'espagnol qui envie la danseuse } \\
\text { adore le spectacle }\end{array}$ & $\begin{array}{l}\text { L'espagnol que la danseuse envie } \\
\text { adore le spectacle }\end{array}$ \\
\hline $\begin{array}{l}\text { L'étudiante renseigne le chômeur et } \\
\text { révise la leçon }\end{array}$ & $\begin{array}{l}\text { L'étudiante qui renseigne le chômeur } \\
\text { révise la leçon }\end{array}$ & $\begin{array}{l}\text { L'étudiante que le chômeur renseigne } \\
\text { révise la leçon }\end{array}$ \\
\hline $\begin{array}{l}\text { L'inspecteur attend la maîtresse et } \\
\text { réclame le silence }\end{array}$ & $\begin{array}{l}\text { L'inspecteur qui attend la maîtresse } \\
\text { réclame le silence }\end{array}$ & $\begin{array}{l}\text { L'inspecteur que la maîtresse attend } \\
\text { réclame le silence }\end{array}$ \\
\hline $\begin{array}{l}\text { L'inventeur revoit l'acheteur et en- } \\
\text { toure le dessin }\end{array}$ & $\begin{array}{l}\text { L'inventeur qui revoit l'acheteur en- } \\
\text { toure le dessin }\end{array}$ & $\begin{array}{l}\text { L'inventeur que l'acheteur revoit en- } \\
\text { toure le dessin }\end{array}$ \\
\hline $\begin{array}{l}\text { L'officier attache la complice et ar- } \\
\text { rache le couteau }\end{array}$ & $\begin{array}{l}\text { L'officier qui attache la complice ar- } \\
\text { rache le couteau }\end{array}$ & $\begin{array}{l}\text { L'officier que la complice attache ar- } \\
\text { rache le couteau }\end{array}$ \\
\hline $\begin{array}{l}\text { La belle-mère détend la fiancée et } \\
\text { arrange les cheveux }\end{array}$ & $\begin{array}{l}\text { La belle-mère qui détend la fiancée } \\
\text { arrange les cheveux }\end{array}$ & $\begin{array}{l}\text { La belle-mère que la fiancée détend } \\
\text { arrange les cheveux }\end{array}$ \\
\hline $\begin{array}{l}\text { La belle-soeur avise le doyen et pré- } \\
\text { voit le séjour }\end{array}$ & $\begin{array}{l}\text { La belle-soeur qui avise le doyen pré- } \\
\text { voit le séjour }\end{array}$ & $\begin{array}{l}\text { La belle-soeur que le doyen avise pré- } \\
\text { voit le séjour }\end{array}$ \\
\hline $\begin{array}{l}\text { La bergère visite le pêcheur et des- } \\
\text { sine la colline }\end{array}$ & $\begin{array}{l}\text { La bergère qui visite le pêcheur des- } \\
\text { sine la colline }\end{array}$ & $\begin{array}{l}\text { La bergère que le pêcheur visite des- } \\
\text { sine la colline }\end{array}$ \\
\hline $\begin{array}{l}\text { La bourgeoise console la gardienne } \\
\text { et mentionne le crédit }\end{array}$ & $\begin{array}{l}\text { La bourgeoise qui console la gar- } \\
\text { dienne mentionne le crédit }\end{array}$ & $\begin{array}{l}\text { La bourgeoise que la gardienne con- } \\
\text { sole mentionne le crédit }\end{array}$ \\
\hline $\begin{array}{l}\text { La caissière accueille le portier et } \\
\text { fournit la tenue }\end{array}$ & $\begin{array}{l}\text { La caissière qui accueille le portier } \\
\text { fournit la tenue }\end{array}$ & $\begin{array}{l}\text { La caissière que le portier accueille } \\
\text { fournit la tenue }\end{array}$ \\
\hline
\end{tabular}




\begin{tabular}{|c|c|c|}
\hline $\begin{array}{l}\text { La championne enchante le plongeur } \\
\text { et réchauffe le plateau }\end{array}$ & $\begin{array}{l}\text { La championne qui enchante le plon- } \\
\text { geur réchauffe le plateau }\end{array}$ & $\begin{array}{l}\text { La championne que le plongeur en- } \\
\text { chante réchauffe le plateau }\end{array}$ \\
\hline $\begin{array}{l}\text { La chanteuse supporte la vedette et } \\
\text { respecte le contrat }\end{array}$ & $\begin{array}{l}\text { La chanteuse qui supporte la vedette } \\
\text { respecte le contrat }\end{array}$ & $\begin{array}{l}\text { La chanteuse que la vedette supporte } \\
\text { respecte le contrat }\end{array}$ \\
\hline $\begin{array}{l}\text { La cliente arrête le vendeur et ap- } \\
\text { porte le manteau }\end{array}$ & $\begin{array}{l}\text { La cliente qui arrête le vendeur ap- } \\
\text { porte le manteau }\end{array}$ & $\begin{array}{l}\text { La cliente que le vendeur arrête ap- } \\
\text { porte le manteau }\end{array}$ \\
\hline $\begin{array}{l}\text { La compagne soutient le cadet et re- } \\
\text { passe le rideau }\end{array}$ & $\begin{array}{l}\text { La compagne qui soutient le cadet re- } \\
\text { passe le rideau }\end{array}$ & $\begin{array}{l}\text { La compagne que le cadet soutient re- } \\
\text { passe le rideau }\end{array}$ \\
\hline $\begin{array}{l}\text { La comtesse installe la servante et } \\
\text { demande le paquet }\end{array}$ & $\begin{array}{l}\text { La comtesse qui installe la servante } \\
\text { demande le paquet }\end{array}$ & $\begin{array}{l}\text { La comtesse que la servante installe } \\
\text { demande le paquet }\end{array}$ \\
\hline $\begin{array}{l}\text { La concierge salue le vieillard et sur- } \\
\text { veille le jardin }\end{array}$ & $\begin{array}{l}\text { La concierge qui salue le vieillard } \\
\text { surveille le jardin }\end{array}$ & $\begin{array}{l}\text { La concierge que le vieillard salue } \\
\text { surveille le jardin }\end{array}$ \\
\hline $\begin{array}{l}\text { La cousine habille la grand-mère et } \\
\text { descend les étages }\end{array}$ & $\begin{array}{l}\text { La cousine qui habille la grand-mère } \\
\text { descend les étages }\end{array}$ & $\begin{array}{l}\text { La cousine que la grand-mère habille } \\
\text { descend les étages }\end{array}$ \\
\hline $\begin{array}{l}\text { La fleuriste arrose la coiffeuse et } \\
\text { échange la monnaie }\end{array}$ & $\begin{array}{l}\text { La fleuriste qui arrose la coiffeuse } \\
\text { échange la monnaie }\end{array}$ & $\begin{array}{l}\text { La fleuriste que la coiffeuse arrose } \\
\text { échange la monnaie }\end{array}$ \\
\hline $\begin{array}{l}\text { La française aborde l'étrangère et } \\
\text { traduit la facture }\end{array}$ & $\begin{array}{l}\text { La française qui aborde l'étrangère } \\
\text { traduit la facture }\end{array}$ & $\begin{array}{l}\text { La française que l'étrangère aborde } \\
\text { traduit la facture }\end{array}$ \\
\hline $\begin{array}{l}\text { La juriste défend la stagiaire et con- } \\
\text { temple le palais }\end{array}$ & $\begin{array}{l}\text { La juriste qui défend la stagiaire con- } \\
\text { temple le palais }\end{array}$ & $\begin{array}{l}\text { La juriste que la stagiaire défend con- } \\
\text { temple le palais }\end{array}$ \\
\hline $\begin{array}{l}\text { La légiste connaît l'infirmière et re- } \\
\text { garde la télé }\end{array}$ & $\begin{array}{l}\text { La légiste qui connaît l'infirmière re- } \\
\text { garde la télé }\end{array}$ & $\begin{array}{l}\text { La légiste que l'infirmière connaît re- } \\
\text { garde la télé }\end{array}$ \\
\hline $\begin{array}{l}\text { La libraire espionne le mendiant et } \\
\text { balaie le trottoir }\end{array}$ & $\begin{array}{l}\text { La libraire qui espionne le mendiant } \\
\text { balaie le trottoir }\end{array}$ & $\begin{array}{l}\text { La libraire que le mendiant espionne } \\
\text { balaie le trottoir }\end{array}$ \\
\hline $\begin{array}{l}\text { La maman conseille le tailleur et re- } \\
\text { joint la maison }\end{array}$ & $\begin{array}{l}\text { La maman qui conseille le tailleur re- } \\
\text { joint la maison }\end{array}$ & $\begin{array}{l}\text { La maman que le tailleur conseille re- } \\
\text { joint la maison }\end{array}$ \\
\hline $\begin{array}{l}\text { La marchande informe la chinoise et } \\
\text { affiche le panneau }\end{array}$ & $\begin{array}{l}\text { La marchande qui informe la chi- } \\
\text { noise affiche le panneau }\end{array}$ & $\begin{array}{l}\text { La marchande que la chinoise in- } \\
\text { forme affiche le panneau }\end{array}$ \\
\hline $\begin{array}{l}\text { La marraine endort la belle-fille et } \\
\text { active le réveil }\end{array}$ & $\begin{array}{l}\text { La marraine qui endort la belle-fille } \\
\text { active le réveil }\end{array}$ & $\begin{array}{l}\text { La marraine que la belle-fille endort } \\
\text { active le réveil }\end{array}$ \\
\hline $\begin{array}{l}\text { La masseuse contraint le coureur et } \\
\text { étend la serviette }\end{array}$ & $\begin{array}{l}\text { La masseuse qui contraint le coureur } \\
\text { étend la serviette }\end{array}$ & $\begin{array}{l}\text { La masseuse que le coureur contraint } \\
\text { étend la serviette }\end{array}$ \\
\hline
\end{tabular}




\begin{tabular}{|c|c|c|}
\hline $\begin{array}{l}\text { La médium inspire l'amoureux et } \\
\text { mérite le tableau }\end{array}$ & $\begin{array}{l}\text { La médium qui inspire l'amoureux } \\
\text { mérite le tableau }\end{array}$ & $\begin{array}{l}\text { La médium que l'amoureux inspire } \\
\text { mérite le tableau }\end{array}$ \\
\hline $\begin{array}{l}\text { La menteuse ignore la coupable et } \\
\text { évite le regard }\end{array}$ & $\begin{array}{l}\text { La menteuse qui ignore la coupable } \\
\text { évite le regard }\end{array}$ & $\begin{array}{l}\text { La menteuse que la coupable ignore } \\
\text { évite le regard }\end{array}$ \\
\hline $\begin{array}{l}\text { La notaire distrait l'analyste et efface } \\
\text { les empreintes }\end{array}$ & $\begin{array}{l}\text { La notaire qui distrait l'analyste ef- } \\
\text { face les empreintes }\end{array}$ & $\begin{array}{l}\text { La notaire que l'analyste distrait ef- } \\
\text { face les empreintes }\end{array}$ \\
\hline $\begin{array}{l}\text { La patronne dérange le malade et ac- } \\
\text { corde la semaine }\end{array}$ & $\begin{array}{l}\text { La patronne qui dérange le malade } \\
\text { accorde la semaine }\end{array}$ & $\begin{array}{l}\text { La patronne que le malade dérange } \\
\text { accorde la semaine }\end{array}$ \\
\hline $\begin{array}{l}\text { La pédiatre critique l'apprenti et } \\
\text { remplit le carnet }\end{array}$ & $\begin{array}{l}\text { La pédiatre qui critique l'apprenti } \\
\text { remplit le carnet }\end{array}$ & $\begin{array}{l}\text { La pédiatre que l'apprenti critique } \\
\text { remplit le carnet }\end{array}$ \\
\hline $\begin{array}{l}\text { La pianiste embrasse la mariée et } \\
\text { augmente la musique }\end{array}$ & $\begin{array}{l}\text { La pianiste qui embrasse la mariée } \\
\text { augmente la musique }\end{array}$ & $\begin{array}{l}\text { La pianiste que la mariée embrasse } \\
\text { augmente la musique }\end{array}$ \\
\hline $\begin{array}{l}\text { La recrue flatte la joueuse et rem- } \\
\text { porte la victoire }\end{array}$ & $\begin{array}{l}\text { La recrue qui flatte la joueuse rem- } \\
\text { porte la victoire }\end{array}$ & $\begin{array}{l}\text { La recrue que la joueuse flatte rem- } \\
\text { porte la victoire }\end{array}$ \\
\hline $\begin{array}{l}\text { La sage-femme tolère la hippie et } \\
\text { dispose le fauteuil }\end{array}$ & $\begin{array}{l}\text { La sage-femme qui tolère la hippie } \\
\text { dispose le fauteuil }\end{array}$ & $\begin{array}{l}\text { La sage-femme que la hippie tolère } \\
\text { dispose le fauteuil }\end{array}$ \\
\hline $\begin{array}{l}\text { La sauvage retient le bonhomme et } \\
\text { comprend le problème }\end{array}$ & $\begin{array}{l}\text { La sauvage qui retient le bonhomme } \\
\text { comprend le problème }\end{array}$ & $\begin{array}{l}\text { La sauvage que le bonhomme retient } \\
\text { comprend le problème }\end{array}$ \\
\hline $\begin{array}{l}\text { La serveuse amuse le mari et oublie } \\
\text { le café }\end{array}$ & $\begin{array}{l}\text { La serveuse qui amuse le mari oublie } \\
\text { le café }\end{array}$ & $\begin{array}{l}\text { La serveuse que le mari amuse oublie } \\
\text { le café }\end{array}$ \\
\hline $\begin{array}{l}\text { La sorcière attire le chasseur et dé- } \\
\text { chire la chemise }\end{array}$ & $\begin{array}{l}\text { La sorcière qui attire le chasseur dé- } \\
\text { chire la chemise }\end{array}$ & $\begin{array}{l}\text { La sorcière que le chasseur attire dé- } \\
\text { chire la chemise }\end{array}$ \\
\hline $\begin{array}{l}\text { La témoin réveille la victime et dé- } \\
\text { marre la voiture }\end{array}$ & $\begin{array}{l}\text { La témoin qui réveille la victime dé- } \\
\text { marre la voiture }\end{array}$ & $\begin{array}{l}\text { La témoin que la victime réveille dé- } \\
\text { marre la voiture }\end{array}$ \\
\hline $\begin{array}{l}\text { La voisine observe l'inconnue et sou- } \\
\text { lève la fenêtre }\end{array}$ & $\begin{array}{l}\text { La voisine qui observe l'inconnue } \\
\text { soulève la fenêtre }\end{array}$ & $\begin{array}{l}\text { La voisine que l'inconnue observe } \\
\text { soulève la fenêtre }\end{array}$ \\
\hline $\begin{array}{l}\text { La voleuse détient le pompiste et dé- } \\
\text { clenche le moteur }\end{array}$ & $\begin{array}{l}\text { La voleuse qui détient le pompiste } \\
\text { déclenche le moteur }\end{array}$ & $\begin{array}{l}\text { La voleuse que le pompiste détient } \\
\text { déclenche le moteur }\end{array}$ \\
\hline $\begin{array}{l}\text { La voyante soulage la gitane et récite } \\
\text { le poème }\end{array}$ & $\begin{array}{l}\text { La voyante qui soulage la gitane ré- } \\
\text { cite le poème }\end{array}$ & $\begin{array}{l}\text { La voyante que la gitane soulage ré- } \\
\text { cite le poème }\end{array}$ \\
\hline $\begin{array}{l}\text { Le bandit occupe la comptable et } \\
\text { emporte le journal }\end{array}$ & $\begin{array}{l}\text { Le bandit qui occupe la comptable } \\
\text { emporte le journal }\end{array}$ & $\begin{array}{l}\text { Le bandit que la comptable occupe } \\
\text { emporte le journal }\end{array}$ \\
\hline
\end{tabular}




\begin{tabular}{|c|c|c|}
\hline $\begin{array}{l}\text { Le barbier imite le dandy et incline } \\
\text { le miroir }\end{array}$ & $\begin{array}{l}\text { Le barbier qui imite le dandy incline } \\
\text { le miroir }\end{array}$ & $\begin{array}{l}\text { Le barbier que le dandy imite incline } \\
\text { le miroir }\end{array}$ \\
\hline $\begin{array}{l}\text { Le batteur accable la mascotte et es- } \\
\text { suie l'instrument }\end{array}$ & $\begin{array}{l}\text { Le batteur qui accable la mascotte es- } \\
\text { suie l'instrument }\end{array}$ & $\begin{array}{l}\text { Le batteur que la mascotte accable es- } \\
\text { suie l'instrument }\end{array}$ \\
\hline $\begin{array}{l}\text { Le boucher provoque la nourrice et } \\
\text { avale le gâteau }\end{array}$ & $\begin{array}{l}\text { Le boucher qui provoque la nourrice } \\
\text { avale le gâteau }\end{array}$ & $\begin{array}{l}\text { Le boucher que la nourrice provoque } \\
\text { avale le gâteau }\end{array}$ \\
\hline $\begin{array}{l}\text { Le boxeur suspecte le vainqueur et } \\
\text { repousse la menace }\end{array}$ & $\begin{array}{l}\text { Le boxeur qui suspecte le vainqueur } \\
\text { repousse la menace }\end{array}$ & $\begin{array}{l}\text { Le boxeur que le vainqueur suspecte } \\
\text { repousse la menace }\end{array}$ \\
\hline $\begin{array}{l}\text { Le chauffeur excuse le parent et al- } \\
\text { lume la radio }\end{array}$ & $\begin{array}{l}\text { Le chauffeur qui excuse le parent al- } \\
\text { lume la radio }\end{array}$ & $\begin{array}{l}\text { Le chauffeur que le parent excuse al- } \\
\text { lume la radio }\end{array}$ \\
\hline $\begin{array}{l}\text { Le chercheur corrige la chimiste et } \\
\text { rassemble les données }\end{array}$ & $\begin{array}{l}\text { Le chercheur qui corrige la chimiste } \\
\text { rassemble les données }\end{array}$ & $\begin{array}{l}\text { Le chercheur que la chimiste corrige } \\
\text { rassemble les données }\end{array}$ \\
\hline $\begin{array}{l}\text { Le comique implique l'interprète et } \\
\text { proclame l'ouverture }\end{array}$ & $\begin{array}{l}\text { Le comique qui implique l'interprète } \\
\text { proclame l'ouverture }\end{array}$ & $\begin{array}{l}\text { Le comique que l'interprète implique } \\
\text { proclame l'ouverture }\end{array}$ \\
\hline $\begin{array}{l}\text { Le curieux caresse la diva et con- } \\
\text { serve le collier }\end{array}$ & $\begin{array}{l}\text { Le curieux qui caresse la diva con- } \\
\text { serve le collier }\end{array}$ & $\begin{array}{l}\text { Le curieux que la diva caresse con- } \\
\text { serve le collier }\end{array}$ \\
\hline $\begin{array}{l}\text { Le docteur recherche la patiente et } \\
\text { achète le cadeau }\end{array}$ & $\begin{array}{l}\text { Le docteur qui recherche la patiente } \\
\text { achète le cadeau }\end{array}$ & $\begin{array}{l}\text { Le docteur que la patiente recherche } \\
\text { achète le cadeau }\end{array}$ \\
\hline $\begin{array}{l}\text { Le garçon entend la gamine et éteint } \\
\text { la lumière }\end{array}$ & $\begin{array}{l}\text { Le garçon qui entend la gamine éteint } \\
\text { la lumière }\end{array}$ & $\begin{array}{l}\text { Le garçon que la gamine entend éteint } \\
\text { la lumière }\end{array}$ \\
\hline $\begin{array}{l}\text { Le gendarme bouscule l'innocente et } \\
\text { referme la cellule }\end{array}$ & $\begin{array}{l}\text { Le gendarme qui bouscule l'inno- } \\
\text { cente referme la cellule }\end{array}$ & $\begin{array}{l}\text { Le gendarme que l'innocente bous- } \\
\text { cule referme la cellule }\end{array}$ \\
\hline $\begin{array}{l}\text { Le génie inscrit l'ingénieur et finit le } \\
\text { travail }\end{array}$ & $\begin{array}{l}\text { Le génie qui inscrit l'ingénieur finit le } \\
\text { travail }\end{array}$ & $\begin{array}{l}\text { Le génie que l'ingénieur inscrit finit le } \\
\text { travail }\end{array}$ \\
\hline $\begin{array}{l}\text { Le gérant affronte le maçon et re- } \\
\text { couvre la piscine }\end{array}$ & $\begin{array}{l}\text { Le gérant qui affronte le maçon re- } \\
\text { couvre la piscine }\end{array}$ & $\begin{array}{l}\text { Le gérant que le maçon affronte re- } \\
\text { couvre la piscine }\end{array}$ \\
\hline $\begin{array}{l}\text { Le glacier fascine la touriste et décrit } \\
\text { les parfums }\end{array}$ & $\begin{array}{l}\text { Le glacier qui fascine la touriste dé- } \\
\text { crit les parfums }\end{array}$ & $\begin{array}{l}\text { Le glacier que la touriste fascine dé- } \\
\text { crit les parfums }\end{array}$ \\
\hline $\begin{array}{l}\text { Le grand-père cherche l'italien et re- } \\
\text { grette le mensonge }\end{array}$ & $\begin{array}{l}\text { Le grand-père qui cherche l'italien re- } \\
\text { grette le mensonge }\end{array}$ & $\begin{array}{l}\text { Le grand-père que l'italien cherche re- } \\
\text { grette le mensonge }\end{array}$ \\
\hline $\begin{array}{l}\text { Le héros libère la déesse et répète la } \\
\text { chanson }\end{array}$ & $\begin{array}{l}\text { Le héros qui libère la déesse répète la } \\
\text { chanson }\end{array}$ & $\begin{array}{l}\text { Le héros que la déesse libère répète la } \\
\text { chanson }\end{array}$ \\
\hline $\begin{array}{l}\text { Le lecteur consulte l'éditeur et il- } \\
\text { lustre le roman }\end{array}$ & $\begin{array}{l}\text { Le lecteur qui consulte l'éditeur il- } \\
\text { lustre le roman }\end{array}$ & $\begin{array}{l}\text { Le lecteur que l'éditeur consulte il- } \\
\text { lustre le roman }\end{array}$ \\
\hline
\end{tabular}




\begin{tabular}{|c|c|c|}
\hline $\begin{array}{l}\text { Le livreur encaisse l'irlandais et ren- } \\
\text { verse le tiroir }\end{array}$ & $\begin{array}{l}\text { Le livreur qui encaisse l'irlandais ren- } \\
\text { verse le tiroir }\end{array}$ & $\begin{array}{l}\text { Le livreur que l'irlandais encaisse ren- } \\
\text { verse le tiroir }\end{array}$ \\
\hline $\begin{array}{l}\text { Le ministre emmène l'avocate et ap- } \\
\text { prend le discours }\end{array}$ & $\begin{array}{l}\text { Le ministre qui emmène l'avocate ap- } \\
\text { prend le discours }\end{array}$ & $\begin{array}{l}\text { Le ministre que l'avocate emmène ap- } \\
\text { prend le discours }\end{array}$ \\
\hline $\begin{array}{l}\text { Le papa retrouve le bébé et attrape la } \\
\text { bouteille }\end{array}$ & $\begin{array}{l}\text { Le papa qui retrouve le bébé attrape } \\
\text { la bouteille }\end{array}$ & $\begin{array}{l}\text { Le papa que le bébé retrouve attrape } \\
\text { la bouteille }\end{array}$ \\
\hline $\begin{array}{l}\text { Le parrain reprend le neveu et refuse } \\
\text { le portable }\end{array}$ & $\begin{array}{l}\text { Le parrain qui reprend le neveu re- } \\
\text { fuse le portable }\end{array}$ & $\begin{array}{l}\text { Le parrain que le neveu reprend re- } \\
\text { fuse le portable }\end{array}$ \\
\hline $\begin{array}{l}\text { Le pilote reçoit le monsieur et amène } \\
\text { les affaires }\end{array}$ & $\begin{array}{l}\text { Le pilote qui reçoit le monsieur } \\
\text { amène les affaires }\end{array}$ & $\begin{array}{l}\text { Le pilote que le monsieur reçoit } \\
\text { amène les affaires }\end{array}$ \\
\hline $\begin{array}{l}\text { Le pompier secourt l'allemande et } \\
\text { abîme le briquet }\end{array}$ & $\begin{array}{l}\text { Le pompier qui secourt l'allemande } \\
\text { abîme le briquet }\end{array}$ & $\begin{array}{l}\text { Le pompier que l'allemande secourt } \\
\text { abîme le briquet }\end{array}$ \\
\hline $\begin{array}{l}\text { Le savant exclut le critique et gas- } \\
\text { pille la peinture }\end{array}$ & $\begin{array}{l}\text { Le savant qui exclut le critique gas- } \\
\text { pille la peinture }\end{array}$ & $\begin{array}{l}\text { Le savant que le critique exclut gas- } \\
\text { pille la peinture }\end{array}$ \\
\hline $\begin{array}{l}\text { Le sculpteur rembourse le plombier } \\
\text { et emballe les jouets }\end{array}$ & $\begin{array}{l}\text { Le sculpteur qui rembourse le plom- } \\
\text { bier emballe les jouets }\end{array}$ & $\begin{array}{l}\text { Le sculpteur que le plombier rem- } \\
\text { bourse emballe les jouets }\end{array}$ \\
\hline $\begin{array}{l}\text { Le seigneur rassure la princesse et } \\
\text { réduit la douleur }\end{array}$ & $\begin{array}{l}\text { Le seigneur qui rassure la princesse } \\
\text { réduit la douleur }\end{array}$ & $\begin{array}{l}\text { Le seigneur que la princesse rassure } \\
\text { réduit la douleur }\end{array}$ \\
\hline $\begin{array}{l}\text { Le sergent écoute le voyou et détruit } \\
\text { le dossier }\end{array}$ & $\begin{array}{l}\text { Le sergent qui écoute le voyou dé- } \\
\text { truit le dossier }\end{array}$ & $\begin{array}{l}\text { Le sergent que le voyou écoute détruit } \\
\text { le dossier }\end{array}$ \\
\hline $\begin{array}{l}\text { Le soldat poursuit le bourreau et pro- } \\
\text { tège le trésor }\end{array}$ & $\begin{array}{l}\text { Le soldat qui poursuit le bourreau } \\
\text { protège le trésor }\end{array}$ & $\begin{array}{l}\text { Le soldat que le bourreau poursuit } \\
\text { protège le trésor }\end{array}$ \\
\hline $\begin{array}{l}\text { Le souverain séduit la duchesse et } \\
\text { honore le royaume }\end{array}$ & $\begin{array}{l}\text { Le souverain qui séduit la duchesse } \\
\text { honore le royaume }\end{array}$ & $\begin{array}{l}\text { Le souverain que la duchesse séduit } \\
\text { honore le royaume }\end{array}$ \\
\hline $\begin{array}{l}\text { Le traiteur relance le commis et cui- } \\
\text { sine la commande }\end{array}$ & $\begin{array}{l}\text { Le traiteur qui relance le commis cui- } \\
\text { sine la commande }\end{array}$ & $\begin{array}{l}\text { Le traiteur que le commis relance cui- } \\
\text { sine la commande }\end{array}$ \\
\hline $\begin{array}{l}\text { Le valet remplace le baron et pré- } \\
\text { sente le salon }\end{array}$ & $\begin{array}{l}\text { Le valet qui remplace le baron pré- } \\
\text { sente le salon }\end{array}$ & $\begin{array}{l}\text { Le valet que le baron remplace pré- } \\
\text { sente le salon }\end{array}$ \\
\hline $\begin{array}{l}\text { Le vigile intrigue la fidèle et dé- } \\
\text { charge le carton }\end{array}$ & $\begin{array}{l}\text { Le vigile qui intrigue la fidèle dé- } \\
\text { charge le carton }\end{array}$ & $\begin{array}{l}\text { Le vigile que la fidèle intrigue dé- } \\
\text { charge le carton }\end{array}$ \\
\hline
\end{tabular}

Table S3. Linguistic material used in the syntactic task (in French). Depending on participants, sentences defined by two animated agents and one inanimate object were presented with each of the three syntactic structures: coordinated clauses (left column), subject relative clauses (middle column) and object relative clauses (right column). 
Movie S1. Tool use Task 
Movie S2. Free-hand Task 